The role of emotions in shaping purchase intentions for innovations using emerging technologies: A scenario-based investigation in the context of nanotechnology

Author names:

Barbara Seegebarth*

Institute of Marketing

Technische Universität Braunschweig

Abt-Jerusalem-Straße 4

38106 Braunschweig, Germany

b.seegebarth@tu-braunschweig.de

Phone: +49 (0)5313913207

Fax +49(0)5313918202

\title{
Christof Backhaus
}

Aston Business School

Marketing and Strategy Group

Aston Triangle

Birmingham, B4 7ET, UK

c.backhaus@aston.ac.uk

Phone: +44 (0)121 2043017

Fax: +44 (0)121 2044917

\section{David M. Woisetschlaeger}

Chair of Services Management and Institute of Automotive Management and Industrial

Production,

Technische Universität Braunschweig

Mühlenpfordtstraße. 23

38106 Braunschweig, Germany

d.woisetschlaeger@tu-braunschweig.de

Phone: +49 (0)53139163120

Fax: +49 53139163123

* Corresponding author 


\section{Funding}

This research did not receive any specific grant from funding agencies in the public, commercial, or not-for-profit sectors.

\section{Declarations of interest:}

'The authors have no conflicts of interest to declare.

Article ahead of print. Please cite as: Seegebarth, B, Backhaus, C, Woisetschläger, DM. The role of emotions in shaping purchase intentions for innovations using emerging technologies: A scenario- based investigation in the context of nanotechnology. Psychol. Mark. 2019; 1- 19.

https://doi.org/10.1002/mar.21228 


\title{
The role of emotions in shaping purchase intentions for innovations using emerging technologies: A scenario-based investigation in the context of nanotechnology
}

\begin{abstract}
Although emotions may not play a major role as antecedents of consumers' innovation acceptance, this study proposes that attitude formation works differently in the context of emerging technologies because of their high levels of uncertainty. To investigate the role of emotions in shaping intentions to adopt innovations using emerging technologies, the conceptual model developed in this study integrates cognitive (risks and benefits) and emotional (optimism and worry) elements. A scenario-based study employing 731 participants tests the model across three nanotechnology-based product innovations that differ in terms of product category risk. The results of a mediated moderation model show that emotions do play a key mediating role in explaining purchase intentions. While the study supports the conceptual model regardless of the level of product-related risk, it finds risk-related differences in the strength and level of the mediational links. By unveiling the role of emotions in emerging technology contexts, this study has important implications not only for innovation management but also for regulating institutions and public policy makers.
\end{abstract}

Keywords: technology acceptance, emerging technologies, decision making under uncertainty, nanotechnology, emotions

Acknowledgments: The authors confirm that they have no conflict of interest.

Article ahead of print. Please cite as: Seegebarth, B, Backhaus, C, Woisetschläger, DM. The role of emotions in shaping purchase intentions for innovations using emerging technologies: A scenario- based investigation in the context of nanotechnology. Psychol. Mark. 2019; 1- 19.

https://doi.org/10.1002/mar.21228 


\section{INTRODUCTION}

Existing approaches to exploring the acceptance of innovative products from a consumer perspective have predominantly taken a rationalist view, drawing on consumers' perceptions of the risks and benefits or value associated with a product (e.g., Venkatesh, Thong, \& Xu, 2012). In some cases, however, rationale-based assessments of risks and benefits are hardly possible: Imagine a situation in which a consumer is standing in front of a supermarket shelf displaying an advertisement for an innovative bandage. The ad promises that this bandage, based on nanotechnology, accelerates the wound-healing process. Though positive at first glance, the innovative product feature may also evoke negative feelings from the mention of nanotechnology, an area in which the long-term consequences of applications have scarcely been explored, making rationale-based assessments of product innovations difficult.

In a more general sense, this example represents an innovation that is based on an emerging technology. Emerging technologies create a range of opportunities, from offering customers better products and services to opening up entirely new markets (Srinivasan, 2008). Defined as "science-based innovations that have the potential to create a new industry or transform an existing one" (Day \& Schoemaker, 2000, p. 2), emerging technologies are distinct from established technologies because of their higher levels of complexity and uncertainty. Incorporating emerging innovations into products and services affords significant benefits and risks, but the long-term consequences of this practice have not yet been thoroughly explored (e.g., Kuzma \& Besley, 2008).

Frequently, emerging technologies are the basis for innovation in complex industrial or research-related applications, such as stem cell treatment, radio-frequency identification, and cloud computing (e.g., Khanagha, Volberda, Sidhu, \& Oshri, 2013; McLaren, 2001). In such 
contexts, users or stakeholders may possess expert knowledge about the potential intended and unintended consequences of their utilization. However, such innovations also have an impact on laypeople, with increasingly more consumer products incorporating product- or process-related innovations that can be classified as emergent. For example, the genetic modification of food products is common practice in a range of markets, and it continuously evokes concerns with ethical, environmental, and health issues (e.g., Klerck \& Sweeney, 2007). Similarly, an increasing number of consumer products draw on nanotechnology (i.e., the incorporation of engineered particles of less than $100 \mathrm{~nm}$ in diameter; Frewer et al., 2011). Applications of these nanotechnologies include toothpaste with whitening effects, sunscreen products with improved features, and powder-based food such as coffee or soup, in which nano-additives prevent lump formation (van Dijk, Fischer, Marvin, \& van Trijp, 2015). The European Commission (2019) estimates the sector involving nanotechnology-based products as exceeding a global volume growth of $€ 2$ trillion.

Regarding attitude formation, an assessment of benefits and, in particular, risks often proves difficult, if not impossible, for two reasons. First, as laypeople, consumers are usually not well informed about the current state of knowledge with regard to the risks involved with such technologies (Priest, Greenhalgh, \& Kramer, 2010). Second, even for informed people or experts on an emerging technology, a rationale-based assessment is hardly possible, as knowledge on the long-term consequences of respective applications is limited (Kuzma \& Besley, 2008). These two aspects contribute to the generally high level of uncertainty characterizing emerging technologies (Day \& Schoemaker, 2000).

If rationale-based assessments of risks and benefits are scarcely possible, how are attitudes and intentions toward the use of innovations based on emerging technologies shaped? 
Advancements in the areas of risk-processing and decision-making theory suggest that emotions play a critical role in decision making under uncertainty (e.g., Slovic, Finucane, Peters, \& MacGregor, 2002). In particular, dual-process theorists propose that emotions are a key mechanism (Slovic, Finucane, Peters, \& MacGregor, 2004). In a similar vein, recent work in the area of consumer attitude formation suggests that emotions along with their valence add explanatory value and thus should be incorporated into models explaining attitude formation (McKechnie, Nath, \& Xun 2018; Taylor, Ishida, \& Donovan 2016). Beyond aspects such as perceived enjoyment, however, theoretical models of technology acceptance have largely ignored the possible role of consumers' emotions related to emerging technologies. This is surprising because, for example, nanotechnology literature similarly proposes that "emotional responses may play a key role in determining acceptance for nanotechnology in general" (Frewer et al., 2011, p. 447).

Against this background, the aim of this paper is twofold. First, building on recent work acknowledging the role of emotions in intention formation (McKechnie et al., 2018; Taylor et al., 2016), this study investigates the interplay between risks or benefits and emotions in explaining purchase intention. Second, it examines differences depending on the general risk related to the purchase category. To accomplish these aims, the conceptual model synthesizes elements from the technology acceptance literature and decision-making theory. The model is tested by employing a scenario-based survey of 731 participants across three types of consumer products that incorporate nanotechnology-based innovations and correspond to different levels of risk perception.

The remainder of the paper proceeds as follows: In the following section, the authors provide an overview of studies that explore the acceptance of innovations using emerging 
technologies and the role of emotions in purchase behavior. Subsequently, they develop the conceptual model and a corresponding set of hypotheses on the direct and interacting effects of perceived benefits and risks as well as optimism and worry. Next, they present the results of the empirical study. Finally, the paper discusses the findings, outlines implications for stakeholders, and gives an outlook for future avenues of research.

\section{LITERATURE REVIEW}

Primarily drawing on theories such as the innovation-diffusion model (Rogers, 2003) or the technology acceptance model (TAM; Davis, Bagozzi, \& Warshaw, 1989) and its more recent extensions (e.g., Venkatesh et al., 2012), the literature on innovation adoption identifies a range of characteristics as antecedents to the adoption (or non-adoption) of market innovations. Product- and innovation-related aspects have been described using terms such as "relative advantage," "convenience," and "complexity" and can, on a more abstract level, be conceptualized as representing either benefits or risks associated with innovation adoption or new product success (e.g., Evanschitzky, Eisend, Calantone, \& Jiang, 2012; Wejnert, 2002). Meta-analytical results from an analysis of 77 empirical consumer innovation adoption studies across different contexts suggest strong effects of both perceived benefits and uncertainty or risks as drivers of adoption intention (Arts, Frambach, \& Bijmolt, 2011). While studies in marketing and innovation management literature are scarce, public policy literature and risk research have devoted considerable effort in investigating the adoption of consumer-market innovations related specifically to emerging technologies. A range of empirical studies has found evidence that perceived benefits and risks shape consumers' attitudes and adoption intentions toward emerging technologies such as biotechnology, gene technology, and nanotechnology (Cacciatore, Scheufele, \& Corley, 2011; for review, see Satterfield, Kandlikar, Beaudrie, Conti, 
$\&$ Harthorn, 2009). In addition, risk-related research provides evidence for a second mechanism - the emotional or affective mechanism - that, separately from benefits and risks, influences consumer perceptions of innovations or applications using emerging technologies (e.g., Siegrist, Stampfli, Kastenholz, \& Keller, 2008).

Building on foundations laid by dual-processing theorists, researchers from varying disciplines have emphasized the crucial roles of emotions, affect, and cognition in decisionmaking processes (Slovic \& Peters, 2006). In contextual settings characterized by high levels of uncertainty and complexity, emotions are particularly important, given that consumers often lack the information and/or knowledge required to cognitively weigh the benefits and risks associated with a consumption decision; instead, they employ heuristics by shifting to an emotional mode of information processing (Lee, Scheufele, \& Lewenstein, 2005). Consequently, cognition-based attempts to understand decision making and attitude formation in the context of emerging technology-related innovations have been extended by integrating affect as an additional antecedent of behavior (Beaudry \& Pinsonneault, 2010). Affect is an umbrella construct that contains specific mental processes such as emotions; emotions reflect a "mental state of readiness that arises from cognitive appraisal of events or thoughts" (Bagozzi, Gopinath, \& Nyer, 1999, p. 184), which in turn evokes specific behavioral activations to affirm or cope with these emotions (Lazarus, 1991).

A review of this literature reveals two major shortcomings of empirical approaches to understanding consumer adoption of innovations using emerging technologies. First, other than affect-related variables such as hedonic benefits, marketing and management literature has largely ignored the importance of affect or emotions as antecedents of product adoption. While public policy and risk literature has increasingly incorporated affect-related aspects into 
empirical models, the slightly different viewpoints of the majority of relevant studies in these areas have led to a focus on negative emotions, leaving the potential role of positive emotions largely neglected (Lee et al., 2005). Second, while several studies have explored the interplay between risks or benefits and (negative) emotions in response to an abstract presentation of an emerging technology, empirical insight is lacking into the competing mechanisms of cognitive and emotional processes at work with regard to the intention to adopt actual applications of emerging technologies.

\section{HYPOTHESES DEVELOPMENT}

\subsection{Consumer perceived benefits and risks}

According to the TAM (Davis et al., 1989), benefits reflect perceived usefulness, defined as the degree to which an individual believes that using a specific system will improve his or her performance. TAM research provides empirical evidence that perceived usefulness predicts users' attitude toward a(n) (emerging) technology (e.g., Yousafzai, Foxall, \& Pallister, 2007), their social acceptance of a technology (Siegrist, 2000), and their acceptance of nanotechnology or their willingness to buy nanotechnology-based products (Cobb \& Macoubrie, 2004). Perceived risk refers to the uncertainty related to and the adverse consequences of buying products or services (Dowling \& Staelin, 1994). A large body of research (for an overview, see Mitchell, 1999) has assessed the impact of perceived risk on consumer behavior (Klerck \& Sweeney, 2007) and, in particular, the inter-relationship between uncertainty/negative consequences and increasing levels of perceived risk (Holak \& Lehmann, 1990; Rijsdijk \& Hultink, 2003). Perceived risk in particular is an important factor in terms of public perception of hazardous emerging technologies (Sjöberg, 2000). For example, consumers associate significant risks with the use of nanotechnology (Cobb \& Macoubrie, 2004; Priest et al., 2010), and research 
has found that the perceived risks of nanotechnology applications decrease consumers' willingness to buy products containing nanoparticles (Stampfli, Siegrist, \& Kastenholz, 2010).

\subsection{Emotions}

While a clear definition is still lacking, different theoretical approaches to uncovering the constituent specifications of emotions have emerged in the past three decades (Richins, 1997). Clore, Ortony, and Foss (1987) refer to emotions as valenced affective reactions that result from perceptions of situations. For example, Bagozzi et al. (1999, p. 184) embed emotions in the umbrella set of mental processes and define them as a "mental state of readiness that arises from cognitive appraisals of events or thoughts." As such, emotions enable individuals to "prioritize and organize behaviors in ways that optimize individual adjustments to the demands of the environment" (Beaudry \& Pinsonneault, 2010, p. 690) and thereby influence behaviors.

Building on basic emotional studies (e.g., Lazarus, 1991), Richins (1997) provides evidence for emotions considered important in the (complex) consumption context. Most of the identified emotions are valenced and relate to positive (e.g., joy, excitement, optimism) or negative (e.g., anger, worry, fear, shame) feelings. In turn, these anticipated positive and negative emotions influence consumer decision making - for example, motivating purchasing or non-purchasing (Bagozzi, Belanche, Casaló, \& Flavián, 2016). Although both groups of emotions are generally relevant in the (emerging) technology acceptance/usage context (Cobb \& Macoubrie, 2004), researchers have predominantly focused on negative emotions (e.g., Lee et al., 2005) or have investigated both types in contexts that are not emerging in nature (Wood \& Moreau, 2006).

Self-determination theory (SDT) sheds light on the mechanisms that can help explain behavioral responses resulting from positive or negative emotions in the context of technology 
acceptance (e.g., Roca \& Gagné, 2008). SDT distinguishes between two overarching types of motivation. Extrinsic motivation refers to activities that result in separable outcomes, while intrinsic motivation involves performing an activity for its own right or because it is inherently interesting (Ryan \& Deci, 2000). Davis, Bagozzi, and Warshaw (1992, p. 1112) define perceived usefulness as extrinsic motivation in terms of performance activities that are perceived as "instrumental in achieving valued outcomes that are distinct from the activity itself." Correspondingly, consumers' perceptions of the benefits/rewards or the risks/negative outcomes of a nanotechnology application can be conceptualized as extrinsic.

By contrast, affect is rooted in intrinsic motivation and subsequently influences technology acceptance (Davis et al., 1992). Researchers have elucidated that extrinsic motivation directly influences intrinsic motivation (Teo, Lim, \& Lai, 1999). Furthermore, previous research indicates that emotions directly influence consumer decision making (Bagozzi et al., 2016; Holbrook \& Batra, 1987; Sherman, Mathur, \& Smith 1997). By incorporating intrinsic motivation into the TAM model, researchers have provided theoretical and empirical evidence for the influence of intrinsic motivation on information technology adoption and usage (for a review, see Lee, Cheung, \& Chen, 2005). From a consumer behavior perspective, several studies reveal differences in the degree to which important outcome variables, such as loyalty intention, product choice or purchase, coping strategies, and satisfaction, are dependent on emotions (e.g., Bagozzi et al., 2016; Taylor et al., 2016; Watson \& Spence, 2007). In their literature review, Beaudry and Pinsonneault (2010) elucidate that positive (negative) emotions significantly increase (decrease) technology usage. Consistent with these findings, Cobb and Macoubrie (2004) and Lee et al. (2005) find that negative emotions toward nanotechnology lead to reduced general support for nanotechnology. 
Considering that in addition to these direct effects, extrinsic and intrinsic motivations are decisive in determining consumer responses (Ryan \& Deci, 2000), emotions serve as a mediator linking perceived usefulness or risks to consumer responses. Research on the relationship between extrinsic and intrinsic motivations proposed in SDT has focused on hedonic influences (e.g., playfulness, joyfulness), but evidence on the role of emotions is scant. Other researchers have conceptualized that emotions mediate the relationship between attitudes or outcome valence and consumer response (e.g., loyalty, purchase intention) (e.g., Bagozzi et al., 2016; Taylor et al., 2016), but empirical approaches are weak in clarifying the mediating role of emotions in linking cognitive evaluations related to the risks and benefits of a product and consumer response in terms of purchase behavior. Accordingly, the current study addresses this research gap.

Consistent with the previous arguments, perceived usefulness, as a positive extrinsic reward associated with nanotechnology applications, is likely to enhance individuals' positive emotions, diminish their negative emotions, and, in turn, positively influence purchase intention toward nanotechnology-based products. By contrast, perceived risks are a negative outcome associated with nanotechnology that reduces individuals' positive emotions, increases their negative emotions, and, in turn, negatively influences purchase intention toward nanotechnology-based products (Figure 1). Thus:

H1a: Perceived usefulness positively influences purchase intention through the mediating mechanism of increased positive emotions.

H1b: Perceived usefulness positively influences purchase intention through the mediating mechanism of decreased negative emotions. 
H2a: Perceived risk negatively influences consumer purchase intention through the mediating mechanism of increased negative emotions.

H2b: Perceived risk negatively influences consumer purchase intention through the mediating mechanism of decreased positive emotions.

-Insert Figure 1 here-

\subsection{Moderator: Product category}

Perceptions of the risks, benefits, importance, and acceptance of nanotechnology can vary across application types and domains (Gupta, Fischer, \& Frewer, 2015). For example, cosmetics and sporting goods based on nanotechnology are associated with fewer benefits than applications of nanotechnology in food packing or medicine (Gupta, Fischer, van der Lans, \& Frewer, 2012). Consumers are more concerned about nanotechnology applications in food and medicine than in electronics (George, Kaptan, Lee, \& Frewer, 2014), and both experts and laypeople believe that risk is higher for food than for cosmetics or medicine applications (i.e., cancer treatments, medical nanorobots) (Siegrist, Keller, Kastenholz, Frey, \& Wiek, 2007). In addition, compared with food-related nanotechnology applications, consumers associate higher benefits and lower risks to medicine-related nanotechnology applications because of their unique potential (van Dijk et al., 2015).

A key factor influencing risk perceptions of nanotechnology applications is the body invasiveness characteristic of nanomaterials (Conti, Satterfield, \& Harthorn, 2011; Siegrist et al., 2007). Bodily invasion is highest when products containing nanoparticles directly enter the body, as in the case of food. In other cases, exposure to nanoparticles is lesser, so the potential adverse health effects related to the controllability of nanomaterials when released may seem less likely. 
Given the novelty of nanotechnology as an emerging technology, consumers are uncertain about its corresponding effects in application use. Nanotechnologies' perceived bodily invasion and the resulting behavioral properties of materials influence risk/benefit judgments (Conti et al., 2011). Conti et al. (2011) empirically demonstrate that bodily invasion of nano-enabled food elicits strong concerns. Given these arguments, it is likely that consumers' risk perceptions of and concerns with nanotechnology applications are amplified when bodily invasion of nanoparticles is more likely. In the case of the three categories under research-"on-skin" medical applications, facial cream, and food - the likelihood of bodily invasion varies. That is, it is likely that nanoparticles will enter the body during the consumption of chocolate, while in the case of facial cream, nanoparticles may (but may not) diffuse into the body during application. In the case of an adhesive bandage, bodily invasion of nanoparticles is less likely than in the cases of chocolate and facial cream because the bandage is applied on the skin. Accordingly, the effect of negative emotions on purchase intention is likely to be amplified when nanotechnology applications are associated with bodily invasion of nanoparticles. Furthermore, the body invasiveness characteristic of nanomaterials also influences risk perceptions of nanotechnology applications (Siegrist et al., 2007). Building on SDT and given consumer concerns with nanotechnology applications, the mediating effect of negative emotions between perceived risk and consumer response is likely to be strengthened when nanotechnology applications are associated with an increased likelihood of bodily invasion of nanoparticles (Figure 1). Thus: H3: Nanotechnology applications associated with higher levels of risk amplify the negative relationship between negative emotions and purchase intention toward the product category (i.e., the negative effect of emotions on purchase intention is stronger when 
nanotechnology applications are associated with a higher likelihood that nanoparticles will enter the human body).

H4: Nanotechnology applications associated with higher levels of risk amplify the negative relationship between perceived risk and purchase intention toward the product category, mediated by negative emotions.

\section{METHOD}

\subsection{Procedure}

The purpose of the study is to empirically test the role of emotions in shaping the intention to purchase innovations using emerging technologies. Nanotechnology is a suitable example of an emerging technology for this study because it provides the technological basis for a multitude of innovations.

To test the conceptual model, after a pretest, a scenario-based study with members of an online panel provider in Germany (respondi) was conducted; the study took approximately 15 minutes. The study included eight scenarios to inform participants about nanotechnology; the information on nanotechnology (i.e., gain framing, order benefit and risk, and uncertainty) was manipulated. The scenarios consisted of four parts. First, participants were introduced to nanotechnology, including a definition and a short description about its functionality. To strengthen the credibility of the information provided, the basic explanation text was labeled as information from a leading German consumer safety group (Stiftung Warentest). Second, the participants received factual information about benefits and risks of nanotechnology applications in line with consumer education on this technology (Federal Ministry of Education and Research, 2013; SCENIHR, 2006). To avoid order effects, two sequences were developed: (1) benefits information followed by risk information and (2) risk information followed by benefits 
information. Scenarios were developed according to the scientific literature on framing, which describes individuals' decision making in terms of losses and gains (e.g., Tversky \& Kahneman, 1981) and empirically examines the elucidation of nanotechnology applications (Siegrist et al., 2007). Third, the study framed uncertainty of long-term effects resulting from nanomaterials. Accordingly, participants in the uncertainty condition were informed that long-term effects of nanomaterials were not yet known in the respected application areas, while participants in the certainty condition did not receive this information.

Finally, participants were randomly assigned to one of three nanotechnology applications (bandage, facial cream, or chocolate) from a specific brand and received additional information on these products, including nanomaterials. They were asked to answer survey questions about the application. The main study included real brands from each of the product categories from the pretest. Participants in two additional control conditions did not receive any specific information on nanotechnology before the product assessment (see the Web Appendix for an overview of the scenarios and Appendix A for an exemplary scenario).

\subsection{Measures}

Exposure to the stimulus was followed by a set of post-scenario questions regarding participants' knowledge about nanotechnology, the information content, source credibility, manipulation check on their consciousness about nanotechnology in the assigned scenario, and their prior use of nanotechnology-based products. An eight item-scale adopted from Block and Keller (1995) and Montoya-Weiss, Voss, and Grewal (2003) served to measure information content; items included "not interesting/interesting," "one-sided/balanced," "unreliable/reliable," "difficult to comprehend/easy to comprehend," "unbelievable/believable," "difficult to follow/easy to follow," "exaggerated/realistic," and "contained very little information/contained a great deal of 
information" (composite reliability $=.941)$. Source credibility was assessed on a single item adopted from Block and Keller (1995). In addition, consumers reported on their prior purchase behavior regarding nanotechnology-based products on a newly created item ("Have you ever bought products involving nanotechnology consciously?"). As a manipulation check, participants indicated how conscious they were of nanotechnology in the assigned product category also on a newly created item ("I am aware that product X of brand Y involves nanotechnology").

To identify consumers' emotions, participants were asked to self-report their positive and negative feelings about the assigned brand containing nanoparticles. Emotions, as mediator variables, were measured with Richins's (1997) emotion scale. Positive emotions involve optimism and excitement, while negative emotions encompass worry and fear. One item, adapted from Aaker and Keller (1990), measured participants' purchase intention toward the assigned product including nanotechnology. Participants also reported the perceived usefulness and perceived risk of the assigned product category that included nanoparticles on a three-item scale, adapted from Frewer, Scholderer, and Bredahl (2003).

As a robustness check, the researchers considered the framing in terms of a gain or a loss and the framing in terms of the elucidation of nanotechnology applications that might affect the relationships proposed in the conceptual model. Previous research on consumers' decisionmaking processes has also identified that habits, or automated behavior that decreases the amount of conscious thought required to act (Cole et al., 2008), influence buying behavior (e.g., Roy, Chintagunta, \& Haldar, 1996). Therefore, habit in terms of (re-)buying a brand was introduced as a control and measured with a single item adapted from Verplanken and Orbell (2003). Because knowledge about nanotechnology can affect consumers' judgment about nanotechnology applications (e.g., Cacciatore et al., 2011), the researchers controlled for 
knowledge using Clarkson, Janiszewski, and Cinelle's (2013) scale, which they adapted to the nanotechnology context. Brand attitude can be a strong predictor of purchase intention (Whan Park, MacInnis, Priester, Eisingerich, \& Iacobucci, 2010), so a reliable and validated attitude scale with three semantic differential items (Simmons \& Becker-Olsen, 2006; Woisetschläger, Backhaus, \& Cornwell, 2017) was used to capture brand attitude. All measures used seven-point Likert scales ( 1 = "strongly disagree," 7 = "strongly agree"). Finally, two sociodemographic characteristics (gender and age) served as controls. Appendix B provides an overview of the scales used in the study.

\subsection{Pretest}

To identify nanotechnology-based product categories that differ in perceived risk, a pretest was conducted with members of an online panel provider (respondi). In total, 202 respondents participated in the survey. The average age of the respondents was 49.7 years $(\mathrm{SD}=14.9)$, and $58 \%$ were men. The respondents evaluated the risk of using nine product categories that incorporate nanotechnology (bathroom cleanser, facial cream, mineral water, outdoor clothes, bandages, sunscreen, sweets, toothpaste, and yogurt) on a seven-point scale ("very low/very high"). The levels of risk perception ranged from $3.39(\mathrm{SD}=1.71)$ for outdoor clothes to 4.96 $(\mathrm{SD}=1.72)$ for sweets (chocolate), ascending with the level of bodily invasion of a nanotechnology application. Given that outdoor clothes are purchased less frequently and have a significantly higher merchandise value than the other categories, three categories with varying levels of usage risk were selected: (1) a bandage, representing relatively low levels of perceived risk $(\mathrm{M}=4.13, \mathrm{SD}=1.76)$ as an "on-skin” application of nanotechnology; (2) facial cream, associated with medium risk levels $(\mathrm{M}=4.47, \mathrm{SD}=1.66)$ as an application absorbed by the skin; and (3) chocolate, a high-risk application $(\mathrm{M}=4.96, \mathrm{SD}=1.72)$ as nanotechnology is 
immediately absorbed into the body. Analysis of variance (ANOVA) indicated that all mean differences were significant $(p<.01)$. In addition, respondents indicated which brands (up to three) they usually choose when buying these nine product categories.

\subsection{Main study participants}

In total, 731 consumers participated in the study $\left(44.3 \%\right.$ female; $\mathrm{M}_{\mathrm{age}}=50.34, \mathrm{SD}=13.72$; education: $15.4 \%$ completed grade school, $57.8 \%$ completed high school, and $25.6 \%$ completed college). Of the participants, $2 \%$ were employed in teaching/education, $7.9 \%$ were students, $47.6 \%$ were employees, $9.5 \%$ were self-employed, $26.9 \%$ were retired, and $6.2 \%$ had another occupation. The participants' income levels were as follows: $€ 1,000$ and under $(16 \%), € 1,001-$ $€ 2,000(28.6 \%), € 2,001-€ 3,000(25.7 \%), € 3,001-€ 4,000(14.9 \%)$, and $€ 4,001$ and above (14.7\%). Participants were randomly assigned to one of the three scenarios: 248 to the bandage product category, 253 to the facial cream category, and 250 to the chocolate category.

\subsection{Data analysis}

Structural equation modeling (SEM) tested the proposed model following Anderson and Gerbing's (1988) two-step approach. First, a confirmatory factor analysis (CFA) with all latent variables was performed on the full sample $(\mathrm{N}=731)$ to assess the measurement model variables using the maximum likelihood estimator in Mplus 7.3 (Muthén \& Muthén, 2012). Second, SEM estimated the parameters of the full sample. Finally, a multi-group analysis was conducted to test the moderation effect and the mediated moderation effect with product categories. Before analysis of group differences in factorial measurement and structural parameters across the three product categories, configural, metric, and scalar invariance was ascertained across groups. To test indirect effects and conditional indirect effects, the suggestion of Preacher, Rucker, and Hayes (2007) was followed and the bootstrapping method used $(\mathrm{N}=10,000)$. 


\section{RESULTS}

\subsection{Scenario comparison}

The results indicate that the scenarios worked as intended, and participants realized that the assigned products involved nanoparticles $(\mathrm{M}=4.66, \mathrm{SD}=2.06)$. No significant differences were detected among product categories $\left(\mathrm{M}_{\text {bandage }}=4.67, \mathrm{SD}=2.04 ; \mathrm{M}_{\text {triail cram }}=4.89, \mathrm{SD}=1.88 ; \mathrm{M}_{\text {chocolate }}=\right.$ $4.42, \mathrm{SD}=2.33 ; F(2,748)=3.233, p>.05)$. In addition, from a sum score of information content (range 8-56), the results indicate that all scenarios provided substantial information value (content) $(M=40.7-42.9)$. Participants evaluated Stiftung Warentest as a credible source $(\mathrm{M}=5.59, \mathrm{SD}=1.29)$, and ANOVA yielded no significant differences among product categories $\left(\mathrm{M}_{\text {bandage }}=5.65, \mathrm{SD}=1.19 ; \mathrm{M}_{\text {fraial cram= }}=5.64, \mathrm{SD}=1.28 ; \mathrm{M}_{\text {choochate }}=5.48, \mathrm{SD}=1.40 ; F(2,748)=\right.$ $1.388, p>.05)$. Predominantly, participants had not consciously chosen products that included nanotechnology in the past $(\mathrm{M}=2.17, \mathrm{SD}=.64)$; again, no significant differences were detected among product categories $\left(\mathrm{M}_{\text {bandage }}=2.13, \mathrm{SD}=.66 ; \mathrm{M}_{\text {frial cram= }}=2.17, \mathrm{SD}=.62 ; \mathrm{M}_{\text {choodalat }}=2.20, \mathrm{SD}\right.$ $=.65 ; F(2,748)=.690, p>.05)$.

\subsection{CFA}

In line with Hu and Bentler's (1998) suggestions, the measurement models of the full sample (N $=731)$ achieved an acceptable overall fit: $\chi / \mathrm{df}=1.94(p=.000)$, confirmatory fit index $(\mathrm{CFI})=$ .989 , Tucker-Lewis index $(\mathrm{TLI})=.986$, root mean square error of approximation $($ RMSEA $)=$ .035 , and standardized root mean square residual $(\mathrm{SRMR})=.03$. Regarding measurement reliability and validity, the composite reliabilities $(\mathrm{CR})$ were above .6 for all constructs $(\mathrm{CR}=$ .907-.979). Discriminant validity was assessed with Fornell and Larcker's (1981) criterion. The criterion was met as the average variance extracted (AVE) by each construct exceeded the squared correlations between all pairs of constructs $(.710>.408)$. Therefore, the reliability and 
validity of the constructs in each sample were well within acceptable boundaries (Bagozzi \& Yi, 1988).

\subsection{Main effects and mediating effects}

The results of the structural model $(\mathrm{N}=731)$ including the control variables yielded a satisfactory fit: $\chi^{2} / \mathrm{df}=1.81(p=.000), \mathrm{CFI}=.987, \mathrm{TLI}=.983, \mathrm{RMSEA}=.033, \mathrm{SRMR}=.035$. Perceived usefulness positively influenced optimism but did not affect worry toward brands containing nanoparticles or purchase intention. By contrast, perceived risk significantly heightened worry and reduced optimism, though the path between perceived risk and purchase intention was not significant. In addition, intention to buy the assigned brands was significantly diminished by worry and reinforced by optimism. The findings of specific indirect effects indicate that optimism and worry acted as central mediators. In particular, optimism fully mediated the relationship between perceived usefulness and purchase intention $(\lambda=.105,95 \%$ confidence interval $[\mathrm{CI}]=.076, .141)$, while no significant mediating effect occurred through worry $(\lambda=.011,95 \% \mathrm{CI}=-.005, .033)$. Perceived risk reduced the intention to buy the assigned brand through worry and optimism; the indirect effects were significant $\left(\lambda_{\text {worry }}=-.102,95 \% \mathrm{CI}=\right.$ $\left.-.137,-.070 ; \lambda_{\text {optimism }}=-.036,95 \% \mathrm{CI}=-.061,-.019\right)$, while the direct effect was not significant. These results provide support for $\mathrm{H}_{1 \mathrm{a}}, \mathrm{H}_{2 \mathrm{a}}$, and $\mathrm{H}_{2 \mathrm{~b}}$ but reject $\mathrm{H}_{1 \mathrm{~b}}$. Furthermore, the total indirect and total effect of perceived risk on purchase intention yielded significantly negative paths $\left(\lambda_{\text {total }}\right.$ indirect $\left.=-.138,95 \% \mathrm{CI}=-.180,-.100 ; \lambda_{\text {total }}=-.201,95 \% \mathrm{CI}=-.267,-.133\right)$, and the total indirect and total effect of perceived usefulness on purchase intention revealed significantly positive paths $\left(\lambda_{\text {lotal idirect }}=.117,95 \% \mathrm{CI}=.083, .156 ; \lambda_{\text {lotal }}=.187,95 \% \mathrm{CI}=.115, .259\right)$. Table 1 reports the results.

-Insert Table 1 here- 
Regarding the control variables, habit was significantly related to perceived usefulness, worry, and purchase intention, and knowledge was significantly related to optimism and perceived usefulness. Table 1 shows that brand attitude was also significantly related to purchase intention, perceived risk, and perceived usefulness. Finally, gender significantly influenced perceived risk, perceived usefulness, and purchase intention, and gain/loss framing was significantly related to perceived risk.

\subsection{Moderation effects}

To test the equivalence of the factorial measurement and structure model across product categories, configural, metric, scalar, and structural invariance was performed on the full sample using multi-group analysis (Table 2). Thus, the measurement models were assessed on each sample by applying CFA to ensure that the datasets for each product category relied on similar patterns of factor loadings (configural invariance). In accordance with $\mathrm{Hu}$ and Bentler (1998), the CFA results showed satisfactory global fit indices in each product category sample, with all standardized item loadings above .6 (see Appendix B). Table 2 also shows configural invariance for the baseline model $\left(\chi^{2} / \mathrm{df}=858.764 / 582, \mathrm{CFI}=.984, \mathrm{TLI}=.982, \mathrm{RMSEA}=.044, \mathrm{SRMR}=\right.$ .040). Discriminant validity was confirmed for each product category sample; the AVE of each construct exceeds the squared correlations between all pairs of constructs (bandage: $.730>.476$; facial cream: $.673>.424$; chocolate: $.709>.399$ ). Invariance of the factor loadings across groups (metric invariance) was not observed, but partial metric invariance was detected (Table 2). For this purpose, two items responsible for metric non-equivalent factor loadings were unconstrained. In addition, to compare latent means, scalar invariance is necessary, but it was not met across groups. A partial scalar invariance test was performed, and one intercept responsible for the scalar inequivalence across groups was unconstrained (Table 2). In addition, Table 2 
shows a good fit of all (partial) invariance models and a low decrease in the CFI value (<.003), fulfilling requirements to perform structural invariance across product categories and latent means.

-Insert Table 2 here-

In each sample, the direct effects were predominantly supported, but not every path differed significantly among the product category samples (Table 1). The negative influence of worry on purchase intention was significantly stronger in the chocolate sample than in the bandage sample but was not significant in the chocolate sample compared with the facial cream sample. Similar effects emerged between worry and purchase intention for bandage and facial cream, resulting in non-significant path differences between the two groups. Thus, $\mathrm{H}_{3}$ is partially supported. In addition, optimism positively influenced purchase intention in each sample, but product category of nanotechnology applications did not moderate this relationship. As with the full model, the control variables were included to assess their influence on all independent and dependent variables in each product category sample (Table 1).

Additional results show that perceived risk was negatively and significantly related to purchase intention for bandage and chocolate, while this relationship was not significant for facial cream. Perceived risk reduced purchase intention significantly more for bandage and facial cream than for chocolate. Conversely, perceived usefulness was unrelated to purchase intention for bandage and chocolate, but the path coefficient for facial cream was positive and significant. However, perceived usefulness raised purchase intention significantly more in the facial cream sample than in the chocolate sample, while there was no difference in the bandage sample. Moreover, none of the relationships between perceived usefulness/risk and positive/negative emotions revealed significant differences across groups. In particular, perceived usefulness 
significantly increased optimism but did not affect worry in any sample. Perceived risk increased worry to a similar extent across all product categories, while perceived risk significantly reduced optimism only in the bandage and chocolate samples.

\subsection{Latent mean differences}

Except for the relationship between worry and purchase intention, the findings of the moderation analysis showed that bandage and chocolate yielded similar relationships for the proposed model. However, ANOVA with latent means performed in Mplus (Appendix C) showed significantly different mean levels between these product categories: Consumers' perceptions of usefulness (risk), their optimism (worry) toward the assigned brand containing nanoparticles, and their purchase intention were significantly lower (higher) for chocolate (bandage). The same was true for differences in the latent mean values between facial cream and chocolate. The latent means did not differ between bandage and facial cream, except for worry, which was significantly lower in the bandage sample, and purchase intention, which was significantly lower in the facial cream sample.

\subsection{Moderated mediation}

Moderated mediation occurs when "mediation relations are contingent on the level of a moderator" (Preacher et al., 2007, p. 193). Accordingly, the findings of specific indirect effects indicated that worry and optimism mediated the relationship between perceived risks/benefits and purchase intention in each sample, except the path from perceived usefulness to purchase intention through worry, which was not significant in each sample. Perceived risk significantly decreased purchase intention through worry and optimism, while perceived usefulness significantly strengthened purchase intention through optimism in each sample. Mediated moderation was observed in two relationships. In support of $\mathrm{H}_{4}$, the indirect effect of perceived 
risk on purchase intention through worry was significantly stronger for chocolate than for bandage and facial cream. Furthermore, facial cream yielded a significantly stronger indirect effect of perceived usefulness on purchase intention through optimism than chocolate. For the remaining specific indirect relationships between perceived usefulness/risk and purchase intention, no mediated moderation effects were observed (Table 1).

In addition, in the facial cream sample, the findings showed full mediation through emotions: The indirect effect of perceived risk on purchase intention through emotions (worry and optimism) revealed significant results, and the direct effect of perceived risk on purchase intention was statistically non-significant. Optimism partially mediated the influence of perceived usefulness on purchase intention; both direct and indirect effects were statistically significant. By contrast, in both the bandage and chocolate samples, the results revealed full mediation through optimism, as there were statistically significant indirect effects but no direct effect. Worry and optimism partially mediated the effect of perceived risk on purchase intention in the bandage and chocolate samples. Finally, with regard to the total indirect and total effects of all independent variables on purchase intention, the results revealed significantly negative total indirect effects of perceived risk on purchase intention in each sample; these effects were significantly stronger for the chocolate sample than for the bandage sample. The total indirect effects of perceived usefulness effects on consumers' intention to purchase were positive and significant in each sample, but no significant path differences were found (Table 1). The negative total effect of perceived risk on purchase intention was significantly stronger for bandage and chocolate than for facial cream. By contrast, the positive total influence of perceived usefulness on purchase intention was significantly stronger for facial cream than for bandage and chocolate.

\subsection{Additional results}


Considering that consumer knowledge plays an important role in judging nanotechnological applications, an additional multi-group comparison was performed with product category and knowledge as moderators. Accordingly, the extent to which the proposed model differed depending on consumer knowledge (high vs. low) within the three product categories was analyzed. CFA showed that the global fit indices met standard requirements in all six groups $\left(\mathrm{CFI}>.962, \mathrm{TLI}>.951, \mathrm{RMSEA}<.075, \mathrm{SRMR}<.061 ; \chi^{2} / \mathrm{df}\right.$ was smaller than 1.72 and significant in five samples). Moreover, all factor loadings were substantially greater than .6 (ranging from .698 to .984), with one exception $(\lambda=.577)$. CR was met for each factor (>.873), AVE was always greater than .5 (>.633), and discriminant validity using the Fornell-Larcker criterion was confirmed in each sample. SEM, again using the maximum likelihood method in Mplus, demonstrated satisfactory global fit indices in all samples: $\chi^{2} / \mathrm{df}<1.58(p<.05)$, CFI $>$ .954, TLI $>.939$, RMSEA $<.069$, and SRMR $<.065$.

The hypotheses on the indirect effects $\left(\mathrm{H}_{1}\right.$ and $\left.\mathrm{H}_{2}\right)$ were partially supported; the perceived benefits (risks) increased (diminished) purchase intention through optimism (worry), except for the chocolate sample with high nanotechnology knowledge (bandage sample with low nanotechnology knowledge). In addition, no mediation occurred for the effect of perceived usefulness on consumer purchase intention through worry for each sample, while the indirect effect of perceived risk on purchase intention through optimism was only significant for both facial cream samples (Table 3).

-Insert Table 3 here-

Before structural invariance was carried out across the six product category $\times$ knowledge groups, configural, metric, and scalar invariance was tested. While metric invariance was not observed, partial metric invariance and scalar invariance were detected (Table 4). Therefore, the 
model could be compared across groups. The results showed that product category of nanotechnology applications and knowledge moderated only the negative relationship between worry and purchase intention. In particular, in the bandage sample, worry decreased purchase intention significantly more strongly for consumers with high knowledge than for consumers with low knowledge. All remaining direct paths were statistically invariant across groups. Within the product categories, knowledge did not moderate the mediating effects of positive (negative) emotions (Table 3). Finally, ANOVA with latent means (Appendix D) showed that the mean level of optimism was significantly lower for consumers with high knowledge in the bandage (chocolate) scenario compared to consumers with low knowledge in the bandage (chocolate) scenario. For facial cream, the latent means of usefulness perceptions were significantly lower for consumers with high knowledge compared to consumers with low knowledge. These findings have important implications for regulation, management, and marketing theory.

-Insert Table 4 here-

\section{DISCUSSION}

The results of the empirical analysis show that emotions mediate the relationship between the cognitive evaluation of nanotechnology applications and behavioral intentions toward these products. This finding confirms the appropriateness of incorporating emotions representing affect into the SDT framework and supports the notion that consumers follow a cognitionaffect-conation pattern in their loyalty formation (Oliver, 1999; Ryan \& Deci, 2000). Prevalent habits may explain behavioral intentions regardless of existing attitudes. Similarly, established brand attitudes exert a positive influence on the perceptions of usefulness and behavioral intentions and lower the perceptions of risk. Moreover, the analysis reveals that consumers have higher risk perceptions of and are more worried about consumption of chocolate than use of a 
bandage or facial cream. Supposedly, consumers grow more skeptical about nanotechnology the closer these ingredients are to their body. The results suggest that consumers perceive nanotechnology ingredients applied to the body's surface as less risky than applications ingested directly into the body. A complementary explanation is that consumers see less value in the application of nanotechnology on the surface for chocolate and therefore react more negatively toward it. This rationale is supported by the finding that consumers evaluate the usefulness of nanotechnologically augmented chocolate as lower than that of the other two product categories.

Extending existing studies in the area, this research shows that both positive and negative emotions exert at least partially mediating influences on consumer responses (Bagozzi et al., 2016; McKechnie et al., 2018; Taylor et al., 2016). Depending on the particular product category, the mix and overall relevance of both positive and negative emotions differ, indicating that product innovations using emerging technologies evoke seemingly conflicting emotional responses. From a theoretical standpoint, the inter-relationship between positive and negative emotions seems to constitute a technology paradox. Technologies such as the Internet, for example, create a rich environment and a feeling of community through social media but also reduce social relationships (Kraut et al., 1998). In the study, a bandage promises a faster healing process, resulting in positive emotions, but conflicts with the negative emotions toward the perceived negative long-term effects of nanotechnology. While both emotions are true, they appear contradictory (Johnson, Bardhi, \& Dunn, 2008). In contrast with cost-benefit equations, in which the costs and benefits are known and relatively stable, a technology paradox involves conditions that constantly shift, which in turn leads to contradictory feelings (Mick \& Fournier, 1998). Similarly, in the context of emerging technologies such as nanotechnology, postmodern 
society is faced with conflict and ambivalence, whereby "polar opposite conditions can simultaneously exist, in the same thing” (Mick \& Fournier, 1998, p. 124).

As with all empirical studies, the current model faces several limitations, which may lead to avenues for further research. First, to test the results, studies could replicate the research design by having consumers choose between different options with or without nanotechnology ingredients in a realistic setting. Second, research could examine the role of consumer knowledge as a moderator of the examined cognition-affect-conation pattern. To close the gap between knowledgeable experts and laypeople, efficient knowledge creation for consumers with almost no (or merely baseline) knowledge is necessary to foster more informed and educated decision making (Cacciatore, Scheufele, \& Corley, 2014). In the age of social media, companies and consumers have less difficulty in obtaining information but a greater risk of relying on false information from biased sources. Further research could conceptualize an institutional arrangement that helps enhance consumer knowledge about highly innovative technologies, such as nanotechnology, in a balanced way to allow informed decision making.

\section{IMPLICATIONS}

Several implications can be inferred from the results of the empirical analysis, which should be of concern for regulating institutions (e.g., governments) and companies that (plan to) use nanotechnology as part of their products. The finding that consumers perceive different levels of usefulness and risk and have different corresponding emotions toward nanotechnology in general and specific nanotechnology-based product categories in particular implies that consumers should be informed about the presence of nanotechnology as an ingredient before purchase. Therefore, labeling is a key requirement that regulators should enforce to enable consumers to reach informed and educated decisions about nanotechnology-based products. While disclosure 
regulation exists in some markets and for some product categories (Meili, Lemke, \& Widmer, 2007), important regulatory gaps remain (e.g., when small-scale ingredients are not required to be specifically mentioned as nano-scaled ingredients; Greenaway, 2012). The results of this study imply that visible disclosure is strongly recommended the closer the nanotechnology use is to the human body, as consumers perceive high risk in consuming modified foods. Furthermore, the results show that better-informed consumers are not necessarily more skeptical of nanotechnology. Informing consumers about nanotechnology could, at least in some categories, lead them to perceive products based on nanotechnology (e.g., bandage) more positively, while it could lead them to perceive others (e.g., chocolate) as risker.

From a corporate perspective, an important finding is that acceptance of nanotechnology as an ingredient varies depending on individual- and category-level differences. Market research would help identify specific determinants and barriers to be aware of from a consumer perspective. This research indicates the need to ensure that the use of nanotechnology is useful and risk-free. Consumers' seem to perceive visual enhancements of products (such as in the chocolate scenario) as less useful than functional advantages (such as in the bandage and facial cream scenarios). In the case of nanotechnology disclosure, consumers seem to forgo the optical advantages, as the perceived risks outweigh the benefits. More important, perceived usefulness alone is not sufficient to reduce fears of risk. The results show that a higher value of usefulness does not reduce worry. This implies the need for additional evidence of the innoxiousness of nanotechnology in its specific application. Again, these conclusions are more significant the closer nanotechnology-based products are to the human body.

Overall, this study suggests the need for research and practice to consider the mediating role of emotions in the adoption of products containing emerging technology ingredients. The results 
show that the degree of bodily invasion amplifies the effect of negative emotions on purchase intention. Consequently, both regulating institutions and companies need to pay special attention to this special type of technology. 


\section{REFERENCES}

Aaker, D. A., \& Keller. K. L. (1990). Consumer evaluations of brand extensions. The Journal of Marketing, 54, 27-41. doi: 10.2307/1252171

Anderson, J. C., \& Gerbing, D. W. (1988). Structural equation modeling in practice: A review and recommended two-step approach. Psychological Bulletin, 103, 411-23. doi:10.1037/0033-2909.103.3.411

Arts, J. W., Frambach, R. T., \& Bijmolt, T. H. (2011). Generalizations on consumer innovation adoption: A meta-analysis on drivers of intention and behavior. International Journal of Research in Marketing, 28, 134-44. doi: 10.1016/j.ijresmar.2010.11.002

Bagozzi, R. P., Belanche, D., Casaló, L. V., \& Flavián, C. (2016). The role of anticipated emotions in purchase intentions. Psychology \& Marketing, 33, 629-645. doi: 10.1002/mar.20905

Bagozzi, R. P., Gopinath, M., \& Nyer, P. U. (1999). The role of emotions in marketing. Journal of the Academy of Marketing Science, 27, 184-206. doi: 10.1177/0092070399272005

Bagozzi, R. P., \& Yi, Y. (1988). On the evaluation of structural equation models. Journal of the Academy of Marketing Science, 16, 74-94. doi: 10.1007/BF02723327

Beaudry, A., \& Pinsonneault, A. (2010). The other side of acceptance: Studying the direct and indirect effects of emotions on information technology use. MIS Quarterly, 34, 689-710. doi: $10.2307 / 25750701$

Block, L. G., \& Keller, P. A. (1995). When to accentuate the negative: The effects of perceived efficacy and message framing on intentions to perform a health-related behavior. Journal of Marketing Research, 32, 192-203. doi: 10.2307/3152047 
Cacciatore, M. A., Scheufele, D. A., \& Corley, E. A. (2011). From enabling technology to applications: The evolution of risk perceptions about nanotechnology. Public Understanding of Science, 20, 385-404. doi: 10.1177/0963662509347815

Cacciatore, M. A., Scheufele, D. A., \& Corley, E. A. (2014). Another (methodological) look at knowledge gaps and the Internet's potential for closing them. Public Understanding of Science, 23, 376-94. doi: 10.1177/0963662512447606

Clarkson, J. J., Janiszewski, C., \& Cinelli, M. D. (2013). The desire for consumption knowledge. Journal of Consumer Research, 39, 1313-29. doi: 10.1086/668535

Clore, G. L., Ortony, A., \& Foss, M. A. (1987). The psychological foundations of the affective lexicon. Journal of Personality and Social Psychology, 53, 751-66. doi: 10.1037/00223514.53.4.751

Cobb, M. D., \& Macoubrie, J. (2004). Public perceptions about nanotechnology: Risks, benefits and trust. Journal of Nanoparticle Research, 6, 395-405. doi: 10.1007/s11051-004-3394-4

Cole, C., Laurent, G., Drolet, A., Ebert, J., Gutchess, A., Lambert-Pandraud, R., ... \& Peters, E. (2008). Decision making and brand choice by older consumers. Marketing Letters, 19, 35565. doi: 10.1007/s11002-008-9058-X

Conti, J., Satterfield, T., \& Harthorn, B. H. (2011). Vulnerability and social justice as factors in emergent US nanotechnology risk perceptions. Risk Analysis, 31, 1734-48. doi: 10.1111/j.1539-6924.2011.01608.x

Davis, F. D., Bagozzi, R. P., \& Warshaw, P. R. (1989). User acceptance of computer technology: A comparison of two theoretical models. Management Science, 35, 982-1003. doi: 10.1287/mnsc.35.8.982 
Davis, F. D., Bagozzi, R. P., \& Warshaw, P. R. (1992). Extrinsic and intrinsic motivation to use computers in the workplace. Journal of Applied Social Psychology, 22, 1111-32. doi:

10.1111/j.1559-1816.1992.tb00945.x

Day, G. S., \& Schoemaker, P. J. (2000). A different game. In G. S. Day, J. P. Schoemaker, \& R. E. Gunther (Eds.), Wharton on managing emerging technologies (pp. 1-23). Hoboken, NJ: Wiley.

Dowling, R.G., \& Staelin, R. (1994). A model of perceived risk and intended risk-handling activity. Journal of Consumer Research, 21, 119-25. doi: 10.1086/209386

European Commission. (2019). Nanomaterials. Retrieved from http://ec.europa.eu/growth/sectors/chemicals/reach/nanomaterials_en.

Evanschitzky, H., Eisend, M., Calantone, R. J., \& Jiang, Y. (2012). Success factors of product innovation: An updated meta-analysis. Journal of Product Innovation Management, 29, 2137. doi: 10.1111/j.1540-5885.2012.00964.X

Federal Ministry of Education and Research. (2013). The Nano effect. Retrieved from http://www.bmbf.de/en/131.php?hilite=nanotechnology.

Fornell, C., \& Larcker, D. F. (1981). Evaluating structural equation models with unobservable variables and measurement error. Journal of Marketing Research, 18, 39-50. doi: $10.2307 / 3151312$.

Frewer, L. J., Bergmann, K., Brennan, M., Lion, R., Meertens, R., Rowe, G., ... \& Vereijken, C. (2011). Consumer response to novel agri-food technologies: Implications for predicting consumer acceptance of emerging food technologies. Trends in Food Science \& Technology, 22, 442-56. doi: 10.1016/j.tifs.2011.05.005 
Frewer, L. J., Scholderer, J., \& Bredahl, L. (2003). Communicating about the risks and benefits of genetically modified foods: The mediating role of trust. Risk Analysis, 23, 1117-33. doi: $10.1111 / \mathrm{j} .0272-4332.2003 .00385 . \mathrm{x}$

George, S., Kaptan, G., Lee, J., \& Frewer, L. (2014). Awareness on adverse effects of nanotechnology increases negative perception among public: Survey study from Singapore. Journal of Nanoparticle Research, 16, 2751. doi: 10.1007/s11051-014-2751-1

Greenaway, T. (2012). Nanoparticles in your food? You're already eating them. Retrieved from http://grist.org/food/nanoparticles-in-your-food-youre-already-eating-them/.

Gupta, N., Fischer, A. R. H., \& Frewer, L. J. (2015). Ethics, risk and benefits associated with different applications of nanotechnology: A comparison of expert and consumer perceptions of drivers of societal acceptance. NanoEthics, 9, 93-108. doi: 10.1007/s11569-015-0222-5

Gupta, N., Fischer, A. R., van der Lans, I. A., \& Frewer, L. J. (2012). Factors influencing societal response of nanotechnology: An expert stakeholder analysis. Journal of Nanoparticle Research, 14, 1-15. doi: 10.1007/s11051-012-0857-x

Holak, S. L., \& Lehmann, D. R. (1990). Purchase intentions and the dimensions of innovation: An exploratory model. Journal of Product Innovation Management, 7, 59-73. doi: $10.1111 / 1540-5885.710059$

Holbrook, M. B., \& Batra, R. (1987). Assessing the role of emotions as mediators of consumer responses to advertising. Journal of Consumer Research, 14, 404-20. doi: 10.1086/209123

Hu, L.-T., \& Bentler, P. M. (1998). Fit indices in covariance structure modeling: Sensitivity to underparameterized model misspecification. Psychological Methods, 3, 424-453. doi:

10.1037/1082-989X.3.4.424 
Johnson, D. S., Bardhi, F., \& Dunn, D. T. (2008). Understanding how technology paradoxes affect customer satisfaction with self-service technology: The role of performance ambiguity and trust in technology. Psychology \& Marketing, 25, 416-43. doi: 10.1002/mar.20218

Khanagha, S., Volberda, H., Sidhu, J., \& Oshri, I. (2013). Management innovation and adoption of emerging technologies: The case of cloud computing. European Management Review, 10, 51-67. doi: 10.1111/emre.12004

Klerck, D., \& Sweeney, J. C. (2007). The effect of knowledge types on consumer-perceived risk and adoption of genetically modified foods. Psychology \& Marketing, 24, 171-93. doi: $10.1002 /$ mar.20157

Kraut, R., Patterson, M., Lundmark, V., Kiesler, S., Mukophadhyay, T., \& Scherlis, W. (1998). Internet paradox: A social technology that reduces social involvement and psychological wellbeing? American Psychologist, 53, 1017-31. doi: 10.1037/0003-066X.53.9.1017

Kuzma, J. \& Besley, J. C. (2008). Ethics of risk analysis and regulatory review: From bio-to nanotechnology. NanoEthics, 2, 149-62. doi: 10.1007/s11569-008-0035-x

Lazarus, R. S. (1991). Progress on a cognitive-motivational-relational theory of emotion. American Psychologist, 46, 819-34. doi: 10.1037/0003-066X.46.8.819

Lee, C. J., Scheufele, D. A., \& Lewenstein, B. V. (2005). Public attitudes toward emerging technologies: Examining the interactive effects of cognitions and affect on public attitudes toward nanotechnology. Science Communication, 27, 240-67. doi: $10.1177 / 1075547005281474$

Lee, M. K., Cheung, C. M., \& Chen, Z. (2005). Acceptance of Internet-based learning medium: The role of extrinsic and intrinsic motivation. Information \& Management, 42, 1095-104. doi: 10.1016/j.im.2003.10.007 
McKechnie, S., Nath, P., \& Xun, J. (2018). New insights into emotion valence and loyalty intentions in relational exchanges. Psychology \& Marketing, 35, 160-169. doi:

10.1002/mar.21077

McLaren, A. 2001. Ethical and social considerations of stem cell research. Nature, 414, 129-31. doi: $10.1038 / 35102194$

Meili, C., Lemke, M., \& Widmer, M. (2007). Regulation of nanotechnology in consumer products. Retrieved from http://www.nanowerk.com/nanotechnology/reports/reportpdf/report107.pdf.

Mick, D. G., \& Fournier, S. (1998). Paradoxes of technology: Consumer cognizance, emotions, and coping strategies. Journal of Consumer Research, 25, 123-43. doi: 10.1086/209531

Mitchell, V. W. (1999). Consumer perceived risk: Conceptualisations and models. European Journal of Marketing, 33, 163-95. doi: 10.1108/03090569910249229

Montoya-Weiss, M. M., Voss, G. B., \& Grewal, D. (2003). Determinants of online channel use and overall satisfaction with a relational, multichannel service provider. Journal of the Academy of Marketing Science, 31, 448-58. doi: 10.1177/0092070303254408

Muthén, L. K., \& Muthén, B. O. (2012). Mplus user's guide, 5th ed. Los Angeles: Muthén \& Muthén.

Oliver, R. (1999). Whence customer loyalty? Journal of Marketing, 63(Special Issue), 33-44. doi: $10.2307 / 1252099$

Preacher, K. J., Rucker, D. D., \& Hayes, A. F. (2007). Addressing moderated mediation hypotheses: Theory, methods, and prescriptions. Multivariate Behavioral Research, 42, 185227. doi: $10.1080 / 00273170701341316$ 
Priest, S., Greenhalgh, T., \& Kramer, V. (2010). Risk perceptions starting to shift? U. S. citizens are forming opinions about nanotechnology. Journal of Nanoparticle Research, 12, 11-20. doi: 10.1007/s11051-009-9789-5

Richins, M. L. (1997). Measuring emotions in the consumption experience. Journal of Consumer Research, 24, 127-46. doi: 10.1086/209499

Rijsdijk, S. A., \& Hultink, E. J. (2003). "Honey, have you seen our hamster?" Consumer evaluations of autonomous domestic products. Journal of Product Innovation Management, 20, 204-216. doi: 10.1111/1540-5885.2003003

Roca, J. C., \& Gagné, M. (2008). Understanding e-learning continuance intention in the workplace: A self-determination theory perspective. Computers in Human Behavior, 24, 1585-604. doi: 10.1016/j.chb.2007.06.001

Rogers, E. M. (2003). Diffusion of innovations. New York: Free Press.

Roy, R., Chintagunta, P. K., \& Haldar, S. (1996). A framework for investigating habits, "The Hand of the Past," and heterogeneity in dynamic brand choice. Marketing Science, 15, 28099. doi: $10.1287 / \mathrm{mksc} \cdot 15.3 .280$

Ryan, R. M., \& Deci, E. L. (2000). Self-determination theory and the facilitation of intrinsic motivation, social development, and well-being. American Psychologist, 55, 68-78. doi: 10.1037/0003-066X.55.1.68

Satterfield, T., Kandlikar, M., Beaudrie, C. E. H., Conti, J., \& Harthorn, B. H. (2009). Anticipating the perceived risk of nanotechnologies. Nature Nanotechnology, 4, 752-8. doi: 10.1038/nnano.2009.265

SCENIHR (2006). The appropriateness of existing methodologies to assess the potential risks associated with engineered and adventitious products of nanotechnologies. European 
Commission, Scientific Committee on Emerging and Newly Identified Health Risks, March 10. Retrieved from http://ec.europa.eu/health/ph_risk/committees/04_scenihr/docs/scenihr_o_003b.pdf.

Sherman, E., Mathur, A., \& Smith, R. B. (1997). Store environment and consumer purchase behavior: Mediating role of consumer emotions. Psychology \& Marketing, 14, 361-378. doi: 10.1002

Siegrist, M. (2000). The influence of trust and perceptions of risks and benefits on the acceptance of gene technology. Risk Analysis, 20, 195-204. 10.1111/0272-4332.202020

Siegrist, M., Keller, C., Kastenholz, H., Frey, S., \& Wiek, A. (2007). Laypeople's and expert's perception of nanotechnology hazards. Risk Analysis, 27, 59-69. doi: 10.1111/j.15396924.2006.00859.x

Siegrist, M., Stampfli, N., Kastenholz, H., \& Keller, C. (2008). Perceived risks and perceived benefits of different nanotechnology foods and nanotechnology food packaging. Appetite, 51, 283-90. doi: 10.1016/j.appet.2008.02.020

Simmons, C. J., \& Becker-Olsen, K. L. (2006). Achieving marketing objectives through social sponsorships. Journal of Marketing, 70(4), 154-169. doi: 10.1509/jmkg.70.4.154

Sjöberg, L. (2000). Specifying factors in radiation risk perception. Scandinavian Journal of Psychology, 41, 169-74. doi: 10.1111/1467-9450.00184

Slovic, P., Finucane, M. L., Peters, E., \& MacGregor, D. G. (2002). Rational actors or rational fools: Implications of the affect heuristic for behavioral economics. Journal of SocioEconomics, 31, 329-342. doi: 10.1016/S1053-5357(02)00174-9 
Slovic, P., Finucane, M. L., Peters, E., \& MacGregor, D. G. (2004). Risk as analysis and risk as feelings: Some thoughts about affect, reason, risk, and rationality. Risk Analysis, 24, 311-22. doi: $10.1111 / \mathrm{j} .0272-4332.2004 .00433 . x$

Slovic, P., \& Peters, E. (2006). Risk perception and affect. Current Directions in Psychological Science, 15, 322-5. doi: 10.1111/j.1467-8721.2006.00461.x

Srinivasan, R. 2008. Sources, characteristics and effects of emerging technologies: Research opportunities in innovation. Industrial Marketing Management, 37, 633-40. doi: 10.1016/j.indmarman.2007.12.003

Stampfli, N., Siegrist, M., \& Kastenholz, H. (2010). Acceptance of nanotechnology in food and food packaging: A path model analysis. Journal of Risk Research, 13, 353-65. doi: $10.1080 / 13669870903233303$

Taylor, S. A., Ishida, C., \& Donovan, L. A. N. (2016). Considering the role of affect and anticipated emotions in the formation of consumer loyalty intentions. Psychology \& Marketing, 33, 814-829. doi: 10.1002/mar.20919

Teo, T. S., Lim, V. K., \& Lai, R. Y. (1999). Intrinsic and extrinsic motivation in Internet usage. Omega, 27, 25-37. doi: 10.1016/S0305-0483(98)00028-0

Tversky, A., \& Kahneman, D. (1981). The framing of decisions and the rationality of choice. Science, 221, 453-458.

van Dijk, H., Fischer, A. R., Marvin, H. J., \& van Trijp, H. C. (2015). Determinants of stakeholders' attitudes towards a new technology: Nanotechnology applications for food, water, energy and medicine. Journal of Risk Research, 20, 1-22. doi: $10.1080 / 13669877.2015 .1057198$ 
Venkatesh, V., Thong, J. Y. L., \& Xu, X. (2012). Consumer acceptance and use of information technology: Extending the unified theory of acceptance and use of technology. MIS Quarterly, $36,157-78$.

Verplanken, B., \& Orbell, S. (2003). Reflections on past behavior: A self-report index of habit strength. Journal of Applied Social Psychology, 33, 1313-30. doi: 10.1111/j.15591816.2003.tb01951.x

Watson, L., \& Spence, M. T. (2007). Causes and consequences of emotions on consumer behaviour: A review and integrative cognitive appraisal theory. European Journal of Marketing, 41, 487-511. doi: 10.1108/03090560710737570

Wejnert, B. (2002). Integrating models of diffusion of innovations: A conceptual framework. Annual Review of Sociology, 28, 297-326. doi: 10.1146/annurev.soc.28.110601.141051

Whan Park, C., MacInnis, D. J., Priester, J., Eisingerich, A. B., \& Iacobucci, D. (2010). Brand attachment and brand attitude strength: Conceptual and empirical differentiation of two critical brand equity drivers. Journal of Marketing, 74(6), 1-17. doi: 10.1509/jmkg.74.6.1

Woisetschläger, D. M., Backhaus, C., \& Cornwell, T. B. (2017). Inferring corporate motives: How deal characteristics shape sponsorship perceptions. Journal of Marketing, 81(5), 121141. doi: $10.1509 / \mathrm{jm} .16 .0082$

Wood, S. L., \& Moreau, C. P. (2006). From fear to loathing? How emotion influences the evaluation and early use of innovations. Journal of Marketing, 70(3), 44-57. doi: 10.1509/jmkg.70.3.44

Yousafzai, S. Y., Foxall, G. R., \& Pallister, J. G. (2007). Technology acceptance: A metaanalysis of the TAM: Part 1. Journal of Modelling in Management, 2, 251-80. doi: $10.1108 / 17465660710834453$ 
TABLE 1 Structural paths, multi-group analysis, and structural invariance moderator product

\begin{tabular}{|c|c|c|c|c|c|}
\hline & $\begin{array}{l}\text { Total } \\
\mathrm{N}=731\end{array}$ & $\begin{array}{l}\text { Bandage } \\
\# 1 \\
\mathrm{~N}=245\end{array}$ & $\begin{array}{l}\text { Facial Cream } \\
\# 2 \\
\mathrm{~N}=241\end{array}$ & $\begin{array}{l}\text { Chocolate } \\
\# 3 \\
\mathrm{~N}=245\end{array}$ & $\Delta \chi^{2}$ \\
\hline Direct Effects & $\beta$ & $\beta$ & $\beta$ & $\beta$ & \\
\hline Perceived Risk $\rightarrow$ Purchase Intention & $-.063 \mathrm{~ns}$ & $-.172^{* *}$ & $.097 \mathrm{~ns}$ & $-.150^{*}$ & $\begin{array}{l}\# 1>\# 2^{* *} \\
\# 2<\# 3^{* *}\end{array}$ \\
\hline Perceived Risk $\rightarrow$ Optimism & $-.163^{* * *}$ & $-.176^{*}$ & $-.120 \mathrm{~ns}$ & $-.147^{*}$ & - \\
\hline Perceived Risk $\rightarrow$ Worry & $.513^{* * *}$ & $.470^{* * *}$ & $.478^{* * *}$ & $.545^{* * *}$ & - \\
\hline Perceived Usefulness $\rightarrow$ Purchase Intention & $.071 \mathrm{~ns}$ & $.057 \mathrm{~ns}$ & $.193^{* *}$ & $-.012 \mathrm{~ns}$ & $\# 2>\# 3^{*}$ \\
\hline Perceived Usefulness $\rightarrow$ Optimism & $.473^{* * * *}$ & $.442^{* * * *}$ & $.518^{* * *}$ & $.431^{* * * *}$ & - \\
\hline Perceived Usefulness $\rightarrow$ Worry & $-.058 \mathrm{~ns}$ & $-.052 \mathrm{~ns}$ & $-.032 \mathrm{~ns}$ & $-.027 \mathrm{~ns}$ & - \\
\hline Optimism $\rightarrow$ Purchase Intention & $.222^{* * * *}$ & $.260^{* * * *}$ & $.277^{* * * *}$ & $.141^{* *}$ & - \\
\hline Worry $\rightarrow$ Purchase Intention & $-.198^{* * *}$ & $-.115^{*}$ & $-.142^{* *}$ & $-.301^{* * *}$ & $\# 1<\# 3^{* * *}$ \\
\hline Indirect Effects & & $\gamma$ or $\beta\left[C I_{95 \%}\right]$ & $\gamma$ or $\beta\left[C_{95 \%}\right]$ & $\gamma$ or $\beta\left[C I_{95 \%}\right]$ & $\Delta \gamma$ or $\beta$ \\
\hline Perceived Risk $\rightarrow$ Purchase Intention & $-.138[-.180 ;-.100]$ & $-.100[-.180 ;-.039]$ & $-.101[-.186 ;-.043]$ & $-.185[-.266 ;-.117]$ & $\# 1<\# 3^{*}$ \\
\hline Perceived Usefulness $\rightarrow$ Purchase Intention & $.117[.083 ; .156]$ & $.121[.066 ; .194]$ & $.148[.081 ; 233]$ & $.069[.014 ; .139]$ & - \\
\hline Perceived Risk $\rightarrow$ Optimism $\rightarrow$ Purchase Intention & $-.036[-.061 ;-.019]$ & $-.046[-.101 ;-.010]$ & $-.033[-.087 ; .-002]$ & $-.021[-.052 ;-.004]$ & - \\
\hline Perceived Risk $\rightarrow$ Worry $\rightarrow$ Purchase Intention & $-.102[-.137 ;-.070]$ & $-.054[-.107 ;-.009]$ & $-.068[-.137 ;-.025]$ & $-.164[-.244 ;-.103]$ & $\begin{array}{l}\# 1<\# 3^{* *} \\
\# 2<\# 3^{*}\end{array}$ \\
\hline Perceived Usefulness $\rightarrow$ Optimism $\rightarrow$ Purchase Intention & $.105[.076 ; .141]$ & $.115[.066 ; .184]$ & $.143[.077 ; .230]$ & $.061[.023 ; .110]$ & $\# 2>\# 3$ \\
\hline Perceived Usefulness $\rightarrow$ Worry $\rightarrow$ Purchase Intention & $.011[-.005 ; .033]$ & $.006[-.009 ; .037]$ & $.005[-.015 ; .035]$ & $.008[-.033 ; .060]$ & - \\
\hline \multicolumn{6}{|l|}{ Total Effects } \\
\hline Perceived Risk $\rightarrow$ Purchase Intention & $-.201[-.267 ;-.133]$ & $-.272[-.396 ;-.138]$ & $-.004[-.108 ; .098]$ & $-.335[-.426 ;-.229]$ & $\begin{array}{l}\# 1>\# 2^{* * *} \\
\# 2<\# 3^{* * * *}\end{array}$ \\
\hline Perceived Usefulness $\rightarrow$ Purchase Intention & $.187[.115 ; .259]$ & $.178[.060 ; .299]$ & $.341[.227 ; .452]$ & $.057[-.053 ; .175]$ & $\begin{array}{l}\# 1<\# 2^{* * *} \\
\# 2>\#^{3 * * *}\end{array}$ \\
\hline
\end{tabular}

${ }_{* * * *}^{*} p<.001,{ }^{* * *} p<.01,{ }^{*} p<.05, \mathrm{~ns}=$ non-significant. Notes: $\gamma$ or $\beta=$ standardized path coefficients; $95 \%$ CI confidence interval of standardized effects for $p<.05$ with bootstrapping (N=10,000).

Significant effects of control variables: Total sample: brand attitude $\rightarrow$ purchase intention $(\beta=.483 ; p<.000)$; knowledge $\rightarrow$ optimism $(\beta=.103 ; p<.001)$; brand attitude $\rightarrow$ perceived risk $(\beta=-.211 ; p<.001)$ brand attitude $\rightarrow$ perceived usefulness $(\beta=.257 ; p<.001)$; knowledge $\rightarrow$ perceived usefulness $(\beta=.088 ; p<.05)$; habit $\rightarrow$ purchase intention $(\beta=.087 ; p<.01)$; gender $\rightarrow$ purchase intention $(\beta=.070 ; p<.01)$; habit $\rightarrow$ worry $(\beta=.084 ; p<.05)$; gender $\rightarrow$ perceived risk $(\beta=-.101 ; p<.01)$; gain/loss $\rightarrow$ perceived risk $(\beta=-.088 ; p<.05)$; habit $\rightarrow$ perceived usefulness $(\beta=.124 ; p<.001)$; gender $\rightarrow$ perceived usefulness $(\beta=.082 ; p<.05)$; Bandage: brand attitude $\rightarrow$ purchase intention $(\beta=.358 ; p<.001)$; knowledge $\rightarrow$ purchase intention $(\beta=-.107 ; p<.01)$; knowledge $\rightarrow$ optimism $(\beta=.119 ; p<.05)$; brand attitude $\rightarrow$ perceived risk $(\beta=-.277 ; p<.001)$; brand attitude $\rightarrow$ perceived usefulness $(\beta=.236 ; p<.001)$; habit $\rightarrow$ purchase intention $(\beta=.177 ; p<.001)$; gender $\rightarrow$ perceived risk $(\beta=-.178 ; p<.01)$; habit $\rightarrow$ perceived usefulness $(\beta=.161 ; p<.05)$; gender $\rightarrow$ perceived usefulness $(\beta=.182 ; p<.01)$. Facial cream: brand attitude $\rightarrow$ purchase intention $(\beta=.475 ; p<.001)$; brand attitude $\rightarrow$ optimism $(\beta=.154 ; p<.01)$; brand attitude $\rightarrow$ worry $(\beta=.134 ; p<.05)$; brand attitude $\rightarrow$ perceived risk $(\beta=-.199 ; p<.01)$; brand attitude $\rightarrow$ perceived usefulness $(\beta=.272 ; p<.001)$; habit $\rightarrow$ purchase intention $(\beta=.160 ; p<.001)$; gender $\rightarrow$ purchase intention $(\beta=.090 ; p<.05)$; habit $\rightarrow$ perceived risk $(\beta=.147 ; p<.05)$; habit $\rightarrow$ worry $(\beta=.141 ; p<.05)$. Chocolate: habit $\rightarrow$ perceived usefulness $(\beta=.135 ; p<.05)$, habit $\rightarrow$ worry $(\beta=.127 ; p<.05)$; habit $\rightarrow$ optimism $(\beta=.161 ; p<.01)$; uncertainty $\rightarrow$ optimism $(\beta=.128 ; p<.05)$; brand attitude $\rightarrow$ perceived risk $(\beta=-.163 ; p<.05)$; brand attitude $\rightarrow$ perceived usefulness $(\beta=.262 ; p<.001)$; brand attitude $\rightarrow$ purchase intention $(\beta=.544 ; p<.001)$; knowledge $\rightarrow$ optimism $(\beta=.160 ; p<.01)$; knowledge $\rightarrow$ perceived risk $(\beta=.151 ; p<.01)$; gender $\rightarrow$ perceived risk $(\beta=-.149 ; p<.01)$. 
TABLE 2 Invariance of measurement models for moderator product

\begin{tabular}{|c|c|c|c|c|c|c|c|c|c|c|}
\hline Full sample (N=751) & $\chi^{2}$ & $\mathrm{df}$ & RMSEA & $\mathrm{CFI}$ & TLI & SRMR & $\Delta \mathrm{CFI}$ & $\Delta \chi^{2}$ & $\Delta \mathrm{df}$ & $p$-value of $\Delta$ \\
\hline Baseline Model & 858.764 & 582 & .044 & .984 & .982 & .040 & & & & \\
\hline Metric Invariance & 927.402 & 626 & .044 & 983 & 981 & .073 & .001 & 68.638 & 44 & $<.01$ \\
\hline Partial Metric Invariance & 913.720 & 622 & .043 & .984 & .982 & .072 & .001 & 13.682 & 4 & $<.01$ \\
\hline Scalar Invariance & 970.511 & 654 & .044 & .982 & .981 & .072 & .002 & 56.791 & 32 & $<.01$ \\
\hline Partial Scalar Invariance & 954.060 & 650 & .043 & .983 & .982 & .072 & .001 & 16.451 & 4 & $<.01$ \\
\hline
\end{tabular}


TABLE 3 Structural paths, multi-group analysis, and structural invariance moderator product $\times$ knowledge

\begin{tabular}{|c|c|c|c|c|c|c|c|c|}
\hline & $\begin{array}{l}\text { Total } \\
\mathrm{N}=731\end{array}$ & $\begin{array}{l}\text { Bandage } \\
\text { Knowledge High }\end{array}$ & $\begin{array}{l}\text { Bandage } \\
\text { Knowledge Low }\end{array}$ & $\begin{array}{l}\text { Facial Cream } \\
\text { Knowledge } \\
\text { High }\end{array}$ & $\begin{array}{l}\text { Facial Cream } \\
\text { Knowledge Low }\end{array}$ & $\begin{array}{l}\text { Chocolate } \\
\text { Knowledge High }\end{array}$ & $\begin{array}{l}\text { Chocolate } \\
\text { Knowledge } \\
\text { Low }\end{array}$ & $\Delta \chi^{2}$ \\
\hline & & $\# 4$ & $\# 5$ & $\# 6$ & $\# 7$ & \#8 & \#9 & \\
\hline & & $\mathrm{N}=371$ & $\mathrm{~N}=124$ & $\mathrm{~N}=119$ & $\mathrm{~N}=122$ & $\mathrm{~N}=120$ & $\mathrm{~N}=125$ & \\
\hline \multicolumn{9}{|l|}{ Direct Effects } \\
\hline Perceived Risk $\rightarrow$ Purchase Intention & $-.071 \mathrm{~ns}$ & $-.152 \mathrm{~ns}$ & $-.180 \mathrm{~ns}$ & $.177 \mathrm{~ns}$ & $-.003 \mathrm{~ns}$ & $-.121 \mathrm{~ns}$ & $-.175^{*}$ & - \\
\hline Perceived Risk $\rightarrow$ Optimism & $-.148^{* * *}$ & $-.102 \mathrm{~ns}$ & $-.287^{*}$ & $-.243^{* *}$ & $.037 \mathrm{~ns}$ & $-.115 \mathrm{~ns}$ & $-.133 \mathrm{~ns}$ & - \\
\hline Perceived Risk $\rightarrow$ Worry & $.514^{* * *}$ & $.533^{* * *}$ & $.436^{* * *}$ & $.544^{* * *}$ & $.393^{* * *}$ & $.460^{* * * *}$ & $.559^{* * *}$ & - \\
\hline $\begin{array}{l}\text { Perceived Usefulness } \rightarrow \text { Purchase } \\
\text { Intention }\end{array}$ & $.066 \mathrm{~ns}$ & $.078 \mathrm{~ns}$ & $.052 \mathrm{~ns}$ & $.195 \mathrm{~ns}$ & $.163^{*}$ & $.085 \mathrm{~ns}$ & $-.114 \mathrm{~ns}$ & - \\
\hline Perceived Usefulness $\rightarrow$ Optimism & $.492^{* * *}$ & $.590^{* * *}$ & $.286^{*}$ & $.528^{* * *}$ & $.479^{* * *}$ & $.395^{* * *}$ & $.407^{* * *}$ & - \\
\hline Perceived Usefulness $\rightarrow$ Worry & $-.057 \mathrm{~ns}$ & $.005 \mathrm{~ns}$ & $-.084 \mathrm{~ns}$ & $-.094 \mathrm{~ns}$ & $-.002 \mathrm{~ns}$ & $-.162 \mathrm{~ns}$ & $.084 \mathrm{~ns}$ & - \\
\hline Optimism $\rightarrow$ Purchase Intention & $.215^{* * * *}$ & $.256^{* * * *}$ & $.231^{* *}$ & $.291^{* *}$ & $.291^{* * * *}$ & $.072 \mathrm{~ns}$ & $.189^{*}$ & - \\
\hline Worry $\rightarrow$ Purchase Intention & $-.197^{* * * *}$ & $-.209^{* *}$ & $-.015 \mathrm{~ns}$ & $-.184 \mathrm{~ns}$ & $-.101 \mathrm{~ns}$ & $-.257^{* * * *}$ & $-.324^{* * *}$ & $\# 1>\# 2^{*}$ \\
\hline Indirect Effects & $\gamma$ or $\beta\left[C I_{95 \%}\right]$ & $\gamma$ or $\beta\left[C I_{95 \%}\right]$ & $\gamma \operatorname{or} \beta\left[C I_{95 \%}\right]$ & $\gamma$ or $\beta\left[C I_{95 \%}\right]$ & $\gamma$ or $\beta\left[C I_{95 \%}\right]$ & $\gamma \operatorname{or} \beta\left[C I_{95 \%}\right]$ & $\gamma \operatorname{or} \beta\left[C \mathrm{CI}_{95 \%}\right]$ & \\
\hline Perceived Risk $\rightarrow$ Purchase Intention & $\begin{array}{l}-.133 \\
{[-.178 ;-.097]}\end{array}$ & $\begin{array}{l}-.137 \\
{[-.239 ;-.059]}\end{array}$ & $\begin{array}{l}-.073 \\
{[-.237 ; .042]}\end{array}$ & $\begin{array}{l}-.171 \\
{[-.374 ;-.063]}\end{array}$ & $\begin{array}{l}-.029 \\
{[-1194 ;-.043]}\end{array}$ & $\begin{array}{l}-.126 \\
{[-.243 ;-.049]}\end{array}$ & $\begin{array}{l}-.207 \\
{[-.332 ;-.110]}\end{array}$ & - \\
\hline Perceived Usefulness $\rightarrow$ Purchase & .117 & .150 & .067 & .171 & .140 & .070 & .050 & - \\
\hline Intention & {$[.083 ; .156]$} & {$[.050 ; .267]$} & {$[.006 ; .185]$} & {$[.064 ; .330]$} & {$[.060 ; .249]$} & {$[-.009 ; .180]$} & {$[-.032 ; .145]$} & \\
\hline Perceived Risk $\rightarrow$ Optimism $\rightarrow$ & -.032 & -.026 & -.066 & -.071 & .011 & -.008 & -.025 & - \\
\hline Purchase Intention & {$[-.054 ;-.015]$} & {$[-.093 ; .018]$} & {$[-.184 ; .-008]$} & {$[-.199 ;-.008]$} & {$[-.041 ;-.064]$} & {$[-.063 ; .003]$} & {$[-.073 ; .000]$} & \\
\hline Perceived Risk $\rightarrow$ Worry $\rightarrow$ Purchase & -.101 & -.111 & -.006 & -.100 & -.040 & -.118 & -.181 & - \\
\hline Intention & {$[-.139 ;-.072]$} & {$[-.197 ;-.047]$} & {$[-.097 ; .077]$} & {$[-.259 ;-.028]$} & {$[-.130 ;-.001]$} & {$[-.229 ;-.044]$} & {$[-.305 ;-.094]$} & \\
\hline Perceived Usefulness $\rightarrow$ Optimism $\rightarrow$ & .106 & .151 & .066 & .154 & $.140[.060 ; .248]$ & .028 & .077 & - \\
\hline Purchase Intention & {$[.076 ; .142]$} & {$[.073 ; .262]$} & {$[.012 ; .179]$} & {$[.046 ; .315]$} & & {$[-.021 ; .098]$} & {$[.025 ; .157]$} & \\
\hline Perceived Usefulness $\rightarrow$ Worry $\rightarrow$ & .011 & -.001 & .001 & .017 & .000 & .042 & -.027 & - \\
\hline Purchase Intention & {$[-.006 ; .031]$} & {$[-.052 ; .046]$} & {$[-.019 ; .039]$} & {$[-.008 ; .095]$} & {$[-.032 ; .031]$} & {$[-.009 ; .135]$} & {$[-.103 ; .044]$} & \\
\hline \multicolumn{9}{|l|}{ Total Effects } \\
\hline Perceived Risk $\rightarrow$ Purchase Intention & $\begin{array}{l}. .204 \\
{[-.269 ;-.138]}\end{array}$ & $\begin{array}{l}-.289 \\
{[-.440 ;-.126]}\end{array}$ & $\begin{array}{l}-.253 \\
{[-.455 ;-.016]}\end{array}$ & $\begin{array}{l}.006 \\
{[-.165 ; .167]}\end{array}$ & $\begin{array}{l}-.032 \\
{[-.152 ; .093]}\end{array}$ & $\begin{array}{l}-.248 \\
{[-.394 ;-.092]}\end{array}$ & $\begin{array}{l}-.382 \\
{[-.519 ;-.223]}\end{array}$ & - \\
\hline Perceived Usefulness $\rightarrow$ Purchase & .184 & .229 & .120 & .366 & .303 & .155 & -.064 & - \\
\hline Intention & {$[.111 ; .254]$} & {$[.056 ; .390]$} & {$[-.047 ; .306]$} & {$[.177 ; .531]$} & {$[.156 ; .436]$} & {$[-.008 ; .325]$} & {$[-.210 ; .102]$} & \\
\hline
\end{tabular}

${ }^{* * *} p<.001,{ }^{* *} p<.01,{ }^{*} p<.05, \mathrm{~ns}=$ non-significant. Notes: $\gamma$ or $\beta=$ standardized path coefficients; $95 \%$ CI confidence interval of standardized effects for $p<.05$ with bootstrapping (N=10,000).

Significant effects of control variables: Total sample: brand attitude $\rightarrow$ purchase intention $(\beta=.484 ; p<.000)$; brand attitude $\rightarrow$ perceived risk $(\beta=-.211 ; p<.001)$; brand attitude $\rightarrow$ perceived usefulness $(\beta=.257 ; p<.001)$; habit $\rightarrow$ purchase intention $(\beta=.086 ; p<.01)$; gender $\rightarrow$ purchase intention $(\beta=.064 ; p<.01)$; habit $\rightarrow$ worry $(\beta=.085 ; p<.05)$; gender $\rightarrow$ perceived risk $(\beta=-.096 ; p<.01)$; gain/loss $\rightarrow$ perceived risk $(\beta=-.088 ; p<.05)$; habit $\rightarrow$ perceived usefulness $(\beta=.130 ; p<.001)$; gender $\rightarrow$ perceived usefulness $(\beta=.095 ; p<.01)$. 
\#1 Bandage knowledge high: brand attitude $\rightarrow$ purchase intention $(\beta=.364 ; p<.001)$; brand attitude $\rightarrow$ perceived risk $(\beta=-.283 ; p<.01)$; brand attitude $\rightarrow$ perceived usefulness $(\beta=.208 ; p<.05)$; habit $\rightarrow$ purchase intention $(\beta=.147 ; p<.05)$; age $\rightarrow$ perceived risk $(\beta=-.214 ; p<.01)$; gender $\rightarrow$ perceived risk $(\beta=-.209 ; p<.01)$; habit $\rightarrow$ perceived usefulness $(\beta=.275 ; p<.01)$; gender $\rightarrow$ perceived usefulness $(\beta=.159 ; p<.05)$ gain/loss $\rightarrow$ worry $(\beta=-.222 ; p<.01)$. \#2 Bandage knowledge low: brand attitude $\rightarrow$ purchase intention $(\beta=.349 ; p<.001)$; brand attitude $\rightarrow$ perceived risk $(\beta=-.305 ; p<.01)$; brand attitude $\rightarrow$ perceived usefulness $(\beta=.263 ; p<.01)$; habit $\rightarrow$ purchase intention $(\beta=.211 ; p<.01)$; gender $\rightarrow$ perceived risk $(\beta=-.179 ; p<.05)$; gain/loss $\rightarrow$ perceived risk $(\beta=-.228 ; p<.01)$; gender $\rightarrow$ perceived usefulness $(\beta=.218 ; p<.01)$; gain/loss $\rightarrow$ perceived usefulness $(\beta=.165 ; p<.05)$

\#3 Facial cream knowledge high: brand attitude $\rightarrow$ purchase intention $(\beta=.424 ; p<.001)$; brand attitude $\rightarrow$ worry $(\beta=.195 ; p<.05)$; brand attitude $\rightarrow$ perceived risk ( $\beta=-.198 ; p<.05)$; brand attitude $\rightarrow$ perceived usefulness $(\beta=.246 ; p<.01)$; habit $\rightarrow$ purchase intention $(\beta=.249 ; p<.001)$; gender $\rightarrow$ purchase intention $(\beta=.134 ; p<.05)$; habit $\rightarrow$ perceived risk $(\beta=.240 ; p<.01)$. \#4 Facial cream knowledge low: brand attitude $\rightarrow$ purchase intention $(\beta=.519 ; p<.001)$; brand attitude $\rightarrow$ optimism $(\beta=.199 ; p<.05)$; brand attitude $\rightarrow$ perceived usefulness $(\beta=.307 ; p<.001)$.

$\# 5$ Chocolate knowledge high: brand attitude $\rightarrow$ purchase intention $(\beta=.541 ; p<.001)$; brand attitude $\rightarrow$ perceived risk $(\beta=-.430 ; p<.001)$; brand attitude $\rightarrow$ perceived usefulness $(\beta=.445 ; p<.001)$; habit $\rightarrow$ optimism $(\beta=.219 ; p<.01)$. \#6 Chocolate knowledge high: brand attitude $\rightarrow$ purchase intention $(\beta=.584 ; p<.001)$; uncertainty $\rightarrow$ optimism $(\beta=.205 ; p<.01)$; gender $\rightarrow$ perceived risk $(\beta=-.188 ; p<.05)$ habit $\rightarrow$ perceived usefulness $(\beta=.297 ; p<.001)$; uncertainty $\rightarrow$ perceived usefulness $(\beta=.204 ; p<.05)$.

TABLE 4 Invariance of measurement models for moderator product $\times$ knowledge

\begin{tabular}{|c|c|c|c|c|c|c|c|c|c|c|}
\hline Full sample $(\mathrm{N}=751)$ & $\chi^{2}$ & df & RMSEA & $\mathrm{CFI}$ & TLI & SRMR & $\Delta \mathrm{CFI}$ & $\Delta \chi^{2}$ & $\Delta \mathrm{df}$ & $p$-value of $\Delta$ \\
\hline Baseline Model & 1044.477 & 726 & .059 & .978 & .973 & .047 & & & & \\
\hline Metric Invariance & 1180.930 & 811 & .060 & .975 & .971 & .134 & .003 & 136.453 & 85 & $<.01$ \\
\hline Partial Metric Invariance & 1165.073 & 801 & .060 & .975 & .972 & .132 & .000 & 15.857 & 10 & $<.01$ \\
\hline Scalar Invariance & 1264.156 & 871 & .060 & .973 & .972 & .134 & .002 & 83.226 & 60 & $<.05$ \\
\hline Partial Scalar Invariance & 1250.338 & 866 & .060 & .974 & .972 & .134 & .001 & 69.408 & 45 & $<.05$ \\
\hline
\end{tabular}




\section{FIGURE 1 Conceptual model}

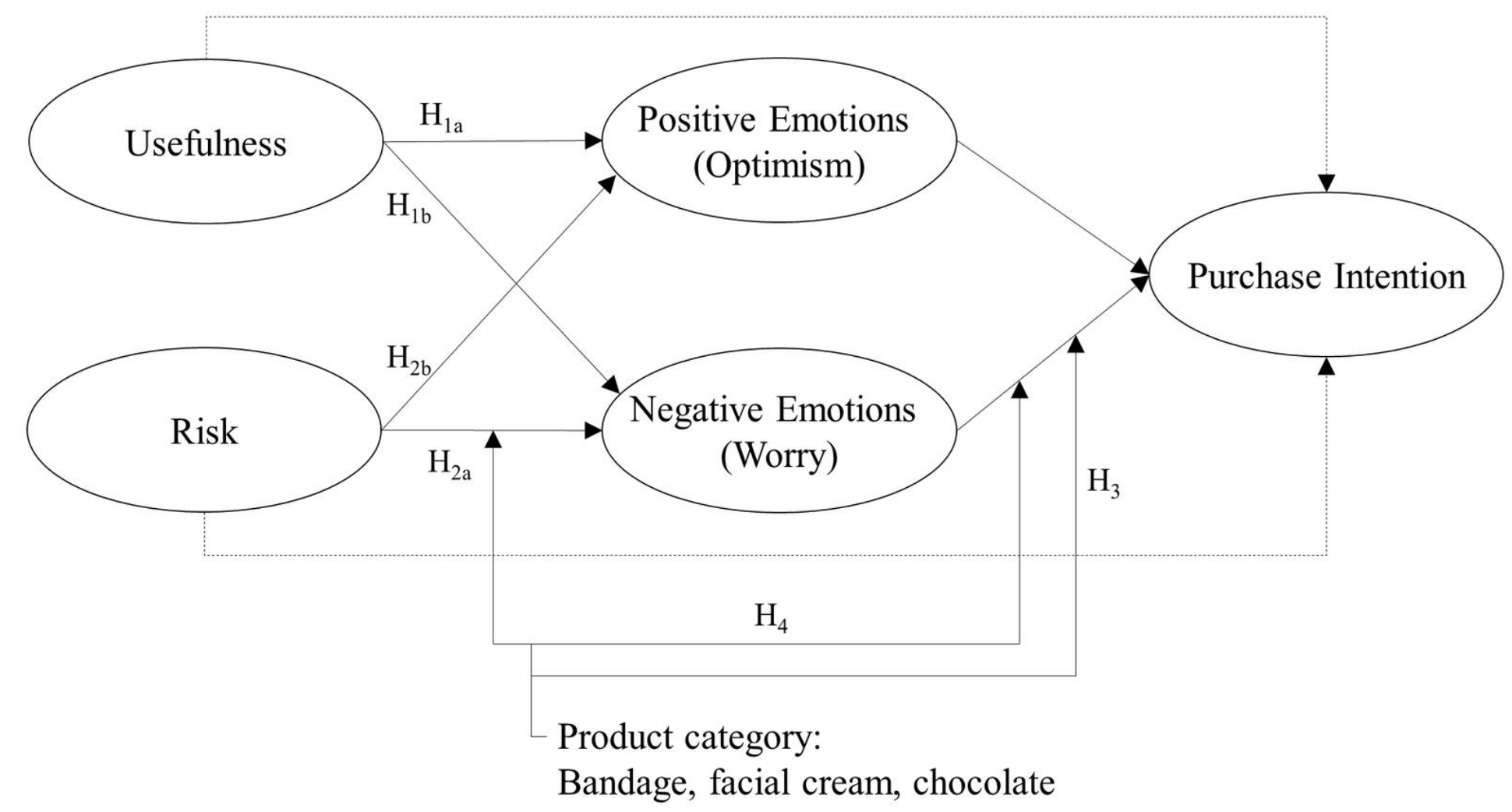




\section{APPENDIX A General introduction to scenarios and scenario example}

\section{GENERAL INTRODUCTION TO SCENARIOS:}

Stiftung Warentest: What is Nanotechnology?

Derived from the Greek term "nanos" (dwarf), "nano" refers to the one-billionth part of a unit/meter (=1 nanometer). Nanoparticles can be described as a compound of a few to less than several thousand atoms or molecules. Increasingly considered a quintessential future technology, nanotechnology is an umbrella term for technologies to explore, develop, construct, and manufacture structures or materials scaled at nanometer size. Materials based on nanotechnology can have new (physical and chemical) properties and functions, for example, higher reactivity.

\section{SCENARIO EXAMPLE}

2. Gain frame, presentation of nanotechnology benefits followed by risks, uncertainty (condition 6)

Which opportunities result from the use of nanotechnology applications? Do risks arise from nanomaterials?

The use of nanotechnology offers a range of opportunities that can be utilized if nanotechnology is deployed in products. Some applications where consumers may benefit from possible advantages are the following:

- Sunscreen: Sunscreen including nanotechnology is transparent and provides high skin compatibility as well as improved UVA and UVB sun protection. Clothing: Textiles using nanotechnology are soil resistant and waterproof.

Medicine: Nanoparticles encapsulated in drugs can be selectively released in organs, thus reducing risky side effects.

- $\quad$ Food packaging: The use of nanotechnology in food packaging kills/destroys germs and bacteria. Thereby, food can be protected and kept fresh for a longer time, so that food waste can be reduced.

Nanotechnology involves a range of risks that can be avoided if nanotechnology is not deployed in products. For consumers who do not use products containing nanoparticles, the following risks exist to a lesser extent:

- Human health: Non-exposure to nanoparticles via usage in conventional products excludes the possibility that nanoparticles will enter the human body and cause harm.

- Environment: Non-exposure to nanoparticles during the production and disposal of conventional products excludes the possibility of harming the environment.

\section{Uncertainty}

Risks associated with nanotechnology are currently being researched intensively. Despite increasing knowledge about nanotechnology, studies on the long-term effects of nanomaterials on human health and the environment have not yet been conducted in all application areas.

4. After receiving the above introduction, participants in the framing conditions were given the following information:

"Currently, nanotechnology is used in many areas of daily life, including in a number of consumer products, such as cosmetics, food and articles of daily use.

Additionally, products from brand [X/Y/Z] include nanotechnology. The advantage of nanotechnology for chocolate (bandage/facial cream) is that it will keep for a longer period of time because the whitish grey coverage (fat bloom) of the chocolate can be reduced (thanks to nanotechnology, bandage produce up to $50 \%$ faster healing/facial cream with nanotechnology encapsulates anti-aging skin care and refines the skin's texture)". 
APPENDIX B Operationalization and scale statistics for moderator product

\begin{tabular}{|c|c|c|c|c|c|c|c|c|c|}
\hline \multirow[t]{2}{*}{ Construct and Items } & \multicolumn{3}{|c|}{ Bandage $(\mathrm{N}=248)$} & \multicolumn{3}{|c|}{ Facial Cream $(\mathrm{N}=253)$} & \multicolumn{3}{|c|}{ Chocolate $(\mathrm{N}=250)$} \\
\hline & \multirow{2}{*}{$\lambda C F A$} & \multirow{2}{*}{\multicolumn{2}{|c|}{$\begin{array}{lr}\mathrm{CR} & \text { AVE } \\
\mathrm{M}=4.29 \mathrm{SD}=1.39\end{array}$}} & $\lambda C F A$ & $\mathrm{CR}$ & AVE & $\lambda C F A$ & $\mathrm{CR}$ & AVE \\
\hline Perceived Usefulness (PU) & & & & \multirow[b]{2}{*}{.986} & \multicolumn{2}{|c|}{$\mathrm{M}=4.18 \mathrm{SD}=1.40$} & \multirow[b]{2}{*}{.974} & \multicolumn{2}{|c|}{$\mathrm{M}=3.42 \mathrm{SD}=1.61$} \\
\hline $\begin{array}{l}\text { 1. Applying nanotechnology to [product] will prove beneficial to the } \\
\text { environment, myself and other people who are important to me. }\end{array}$ & .979 & \multirow[t]{3}{*}{.978} & .936 & & .977 & .935 & & .978 & .938 \\
\hline $\begin{array}{l}\text { 2. Applying nanotechnology to [product] will offer great benefits to } \\
\text { the environment, myself, and other people who are important to me. }\end{array}$ & .960 & & & .954 & & & .974 & & \\
\hline $\begin{array}{l}\text { 3. Applying nanotechnology to [product] will prove advantageous to } \\
\text { the environment, myself, and other people who are important to me. }\end{array}$ & .964 & & & .960 & & & .957 & & \\
\hline Perceived Risk (PR) & & \multicolumn{2}{|c|}{$\mathrm{M}=3.69 \mathrm{SD}=1.47$} & & \multicolumn{2}{|c|}{$\mathrm{M}=3.96 \mathrm{SD}=1.42$} & & \multicolumn{2}{|c|}{$\mathrm{M}=4.45 \mathrm{SD}=1.50$} \\
\hline $\begin{array}{l}\text { 1. Applying nanotechnology to [product] involves considerable risk to } \\
\text { the environment, myself, and other people who are important to me. }\end{array}$ & .962 & \multirow[t]{3}{*}{.961} & \multirow[t]{3}{*}{.893} & .941 & \multirow[t]{3}{*}{.950} & \multirow[t]{3}{*}{.863} & .943 & \multirow[t]{3}{*}{.936} & \multirow[t]{3}{*}{.830} \\
\hline $\begin{array}{l}\text { 2. Applying nanotechnology to [product] will prove harmful to the } \\
\text { environment, myself, and other people who are important to me. }\end{array}$ & .968 & & & .951 & & & .932 & & \\
\hline $\begin{array}{l}\text { 3. Applying nanotechnology [product] will prove disadvantageous to } \\
\text { the environment, myself, and other people who are important to me. }\end{array}$ & .903 & & & .894 & & & .855 & & \\
\hline Optimism (OPT) & & \multicolumn{2}{|c|}{$\mathrm{M}=3.82 \mathrm{SD}=1.46$} & & $\mathrm{M}=3.81$ & $=1.41$ & & $\mathrm{M}=2.9$ & $\mathrm{D}=1.46$ \\
\hline 1. If I think of [product] including nanoparticles, I feel hopeful. & .883 & .929 & .767 & .931 & .907 & .712 & .894 & .930 & .770 \\
\hline 2. If I think of [product] including nanoparticles, I feel optimistic. & .870 & & & .877 & & & .865 & & \\
\hline 3. If I think of [product] including nanoparticles, I feel encouraged. & .867 & & & .643 & & & .864 & & \\
\hline 4. If I think of [product] including nanoparticles, I feel excited. ${ }^{1}$ & - & & & - & & & - & & \\
\hline 5. If I think of [product] including nanoparticles, I feel enthusiastic. ${ }^{1}$ & - & & & - & & & - & & \\
\hline 6. If I think of [product] including nanoparticles, I feel thrilled. & .881 & & & .893 & & & .886 & & \\
\hline Worry $($ WOR $)$ & & $\mathrm{M}=2$ & $\mathrm{D}=1.46$ & & $\mathrm{M}=3.21$ & $=1.49$ & & $\mathrm{M}=3.6$ & $\mathrm{D}=1.64$ \\
\hline 1. If I think of [product] including nanoparticles, I feel nervous. & .935 & .915 & .730 & .841 & .891 & .673 & .883 & .907 & .709 \\
\hline 2. If I think of [product] including nanoparticles, I feel worried. & .761 & & & .733 & & & .854 & & \\
\hline 3. If I think of [product] including nanoparticles, I feel tense. & .798 & & & .860 & & & .761 & & \\
\hline 4. If I think of [product] including nanoparticles, I feel scared. & .910 & & & .842 & & & .865 & & \\
\hline 5. If I think of [product] including nanoparticles, I feel afraid. ${ }^{1}$ & - & & & - & & & - & & \\
\hline 6. If I think of [product] including nanoparticles, I feel panicky. ${ }^{1}$ & - & & & - & & & - & & \\
\hline Purchase Intention (PI) & & & & & & & & & \\
\hline $\begin{array}{l}\text { 1. When buying [product] next time I predict that I will choose a } \\
\text { product using nanotechnology. }\end{array}$ & 1.000 & $\mathrm{M}=5$. & $\mathrm{D}=1.52$ & 1.000 & $\mathrm{M}=4.81$ & $=2.00$ & 1.000 & $\mathrm{M}=4.4$ & $\mathrm{D}=2.06$ \\
\hline Covariates & & & & & & & & & \\
\hline Brand Attitude (BATT) & & $\mathrm{M}=5$. & $\mathrm{D}=1.09$ & & $\mathrm{M}=5.58$ & $=1.27$ & & $\mathrm{M}=5.4$ & $\mathrm{D}=1.38$ \\
\hline 1. Brand $[\mathrm{X} / \mathrm{Y} / \mathrm{Z}]$ is negative/positive. & .978 & .967 & 907 & .965 & .968 & .910 & .975 & .956 & .880 \\
\hline 2. Brand $[\mathrm{X} / \mathrm{Y} / \mathrm{Z}]$ is unfavorable/favorable. & .941 & & & .947 & & & .869 & & \\
\hline 3. Brand $[\mathrm{X} / \mathrm{Y} / \mathrm{Z}]$ is bad/good. & .937 & & & .950 & & & .966 & & \\
\hline Knowledge (KNOW) & & $\mathrm{M}=2$. & $\mathrm{SD}=1.41$ & & $\mathrm{M}=3.01$ & $=1.53$ & & $\mathrm{M}=2.78$ & $\mathrm{D}=1.41$ \\
\hline 1. Knowledge ("not knowledgeable at all/very knowledgeable") & .949 & .957 & .818 & .920 & .948 & .787 & .959 & .946 & .779 \\
\hline 2. Expertise ("not much expertise at all/substantial expertise") & .909 & & & .889 & & & .871 & & \\
\hline 3. Information ("not much information at all/substantial information") & .961 & & & .936 & & & .946 & & \\
\hline $\begin{array}{l}\text { 4. Understanding ("not much understanding at all/substantial } \\
\text { understanding") }\end{array}$ & .824 & & & .861 & & & .820 & & \\
\hline 5. Opinion ("a clear opinion/no clear opinion") & .873 & & & .824 & & & .806 & & \\
\hline Habit & & $\mathrm{M}=4$. & $\mathrm{D}=1.78$ & & $\mathrm{M}=4.32$ & $=2.03$ & & $\mathrm{M}=3.90$ & $\mathrm{D}=1.96$ \\
\hline $\begin{array}{l}\text { 1. I always buy the same brand }[\mathrm{X} / \mathrm{Y} / \mathrm{Z}] \text { without thinking much about } \\
\text { it. }\end{array}$ & 1.000 & & & 1.000 & & & 1.000 & & \\
\hline$\chi^{2 / d f}(p)$ & $1.33(.000$ & & & $1.54(.00$ & & & $1.55(.00$ & & \\
\hline
\end{tabular}




\begin{tabular}{llll} 
RMSEA & .037 & .046 & \\
CFI & .988 & .980 & .047 \\
TLI & .986 & .975 & .979 \\
SRMR & .026 & .046 & .975 \\
\hline
\end{tabular}

${ }^{1}$ Items were excluded from further data analysis owing to their poor item reliability. Notes: [product] = bandage/facial cream/chocolate; [product] refer to branded products in the assigned scenario; $\lambda \mathrm{CFA}=$ factor loadings of the confirmatory factor analysis; $\mathrm{M}=$ mean value; $\mathrm{SD}=$ standard deviation.

APPENDIX C Latent means and comparison of latent means for moderator product

\begin{tabular}{llll}
\hline & $\begin{array}{l}\text { Bandage vs. Facial Cream } \\
\# 1 \text { vs. } \# 2\end{array}$ & $\begin{array}{l}\text { Bandage vs. Chocolate } \\
\# 1 \text { vs. \#3 }\end{array}$ \\
\hline Construct & $\Delta$ Latent mean (SE) and $p$-value of $\Delta$ & $\Delta$ Latent mean (SE) and $p$-value of $\Delta$ & $\Delta$ Latent mean (SE) and $p$-value of $\Delta$ \\
\hline Perceived Usefulness & $-.088(.09) \mathrm{ns}$ & $-.598(.09)^{* * *}$ & $.514(.09)^{* * *}$ \\
Perceived Risk & $.165(.09) \mathrm{ns}$ & $-.501(.09)^{* * * *}$ \\
Optimism & $.003(.09) \mathrm{ns}$ & $.659(.09)^{* * * *}$ & $-.489(.09)^{* * *}$ \\
Worry & $.199(.09)^{*}$ & $-.497(.08)^{* * * *}$ & $-.065(.09)^{* * * *}$ \\
Purchase Intention & $-.291(.09)^{*}$ & $-.029(.09) \mathrm{ns}$ & $-.197(.09)^{* * *}$ \\
Knowledge & $.109(.09) \mathrm{ns}$ & $-.294(.09)^{* * *}$ & $-.135(.09) \mathrm{ns}$ \\
Brand Attitude & $-.211(.09)^{*}$ & $-.077(.09) \mathrm{ns}$ \\
\hline
\end{tabular}

${ }^{* * * *} p<.001,{ }^{* *} p<.01,{ }^{*} p<.05, \mathrm{~ns}=$ non-significant. Notes: $\mathrm{SE}=$ standard error; reading example: participants in bandage group perceive significantly less risk than participants in the chocolate scenario.

APPENDIX D Latent means and comparison of latent means for moderator product $\times$ knowledge

\begin{tabular}{llll}
\hline & $\begin{array}{l}\text { Bandage Knowledge High vs. } \\
\text { Bandage Knowledge Low } \\
\# 4 \text { vs. \#5 }\end{array}$ & $\begin{array}{l}\text { Facial Cream Knowledge High vs. } \\
\text { Facial Cream Knowledge Low } \\
\# 6 \text { vs. \#7 }\end{array}$ \\
\hline Construct & $\Delta$ Latent mean $($ SE) and $p$-value of $\Delta$ & $\Delta$ Latent mean $($ SE) and $p$-value of $\Delta$ & $\Delta$ Latent mean $($ SE) and $p$-value of $\Delta$ \\
\hline Perceived Usefulness & $-.146(.13) \mathrm{ns}$ & $-.285(.13)^{*}$ & $-.124(.13) \mathrm{ns}$ \\
Perceived Risk & $-.069(.13) \mathrm{ns}$ & $-.120(.13) \mathrm{ns}$ & $-.105(.13) \mathrm{ns}$ \\
Optimism & $-.272(.13)^{*}$ & $-.237(.13) \mathrm{ns}$ & $-.307(.13)^{*}$ \\
Worry & $-.091(.13) \mathrm{ns}$ & $-.080(.13) \mathrm{ns}$ & $.129(.13) \mathrm{ns}$ \\
Purchase Intention & $.144(.13) \mathrm{ns}$ & $-.231(.13) \mathrm{ns}$ & $-017(.14) \mathrm{ns}$ \\
Brand Attitude & $-.004(.13) \mathrm{ns}$ & $-.005(.13) \mathrm{ns}$ & \\
\hline
\end{tabular}

${ }^{* * * *} p<.001,{ }^{* *} p<.01,{ }^{*} p<.05, \mathrm{~ns}=$ non-significant. Notes: $\mathrm{SE}=$ standard error. 